\title{
Deregulation of PPAR $\beta / \delta$ target genes in tumor-associated macrophages by fatty acid ligands in the ovarian cancer microenvironment
}

\author{
Tim Schumann ${ }^{1, *}$, Till Adhikary ${ }^{1, *}$, Annika Wortmann ${ }^{1, *}$, Florian Finkernagel ${ }^{1}$, \\ Sonja Lieber ${ }^{1}$, Evelyn Schnitzer ${ }^{1}$, Nathalie Legrand ${ }^{1}$, Yvonne Schober ${ }^{2}$, W. Andreas \\ Nockher ${ }^{2}$, Philipp M. Toth ${ }^{3}$, Wibke E. Diederich ${ }^{3}$, Andrea Nist ${ }^{4}$, Thorsten Stiewe ${ }^{4}$, \\ Uwe Wagner ${ }^{5}$, Silke Reinartz ${ }^{5}$, Sabine Müller-Brüsselbach ${ }^{1}$ and Rolf Müller ${ }^{1}$ \\ ${ }^{1}$ Institute of Molecular Biology and Tumor Research (IMT), Philipps University, Marburg, Germany \\ ${ }^{2}$ Metabolomics Core Facility and Institute of Laboratory Medicine and Pathobiochemistry, Philipps University, Marburg, \\ Germany \\ ${ }^{3}$ Medicinal Chemistry Core Facility and Institute of Pharmaceutical Chemistry, Philipps University, Marburg, Germany \\ ${ }^{4}$ Genomics Core Facility, Philipps University, Marburg, Germany \\ ${ }^{5}$ Clinic for Gynecology, Gynecological Oncology and Gynecological Endocrinology, Center for Tumor Biology and Immunology \\ (ZTI), Philipps University, Marburg, Germany \\ * These authors have contributed equally to this work \\ Correspondence to: Rolf Müller, email: rmueller@imt.uni-marburg.de

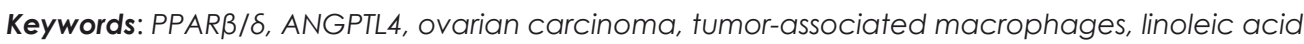 \\ Received: December 23, $2014 \quad$ Accepted: March 29, 2015 \\ Published: April 15, 2015
}

This is an open-access article distributed under the terms of the Creative Commons Attribution License, which permits unrestricted use, distribution, and reproduction in any medium, provided the original author and source are credited.

\section{ABSTRACT}

The nuclear receptor peroxisome proliferator-activated receptor $\beta / \delta$ (PPAR $\beta / \delta$ ) is a lipid ligand-inducible transcription factor associated with macrophage polarization. However, its function in tumor-associated macrophages (TAMs) has not been investigated to date. Here, we report the PPAR $\beta / \delta$-regulated transcriptome and cistrome for TAMs from ovarian carcinoma patients. Comparison with monocytederived macrophages shows that the vast majority of direct PPAR $\beta / \delta$ target genes are upregulated in TAMs and largely refractory to synthetic agonists, but repressible by inverse agonists. Besides genes with metabolic functions, these include cell typeselective genes associated with immune regulation and tumor progression, e.g., LRP5, CD300A, MAP3K8 and ANGPTL4. This deregulation is not due to increased expression of PPAR $\beta / \delta$ or its enhanced recruitment to target genes. Instead, lipidomic analysis of malignancy-associated ascites revealed high concentrations of polyunsaturated fatty acids, in particular linoleic acid, acting as potent PPAR $\beta / \delta$ agonists in macrophages. These fatty acid ligands accumulate in lipid droplets in TAMs, thereby providing a reservoir of PPAR $\beta / \delta$ ligands. These observations suggest that the deregulation of PPAR $\beta / \delta$ target genes by ligands of the tumor microenvironment contributes to the pro-tumorigenic polarization of ovarian carcinoma TAMs. This conclusion is supported by the association of high ANGPTL4 expression with a shorter relapse-free survival in serous ovarian carcinoma.

\section{INTRODUCTION}

Macrophages of the tumor microenvironment play a pivotal role in promoting the growth, invasion, metastazation and therapy resistance of malignant tumors, as suggested by the correlation of disease progression with macrophage density in different types of human cancer and shown in mouse tumor models $[1,2]$. Under the influence of chemokines, cytokines and growth factors secreted by tumor cells and other host-derived cells, monocytes are recruited from the circulation and differentiate into tumorassociated macrophages (TAMs) that are programmed 
to promote tumor progression [3-5]. Macrophages react to their microenvironment with an extreme plasticity [6], resulting in highly diverse phenotypes, with proinflammatory "M1" and anti-inflammatory "M2" macrophages [4] as the extremes. Macrophages can also adopt mixed-polarization phenotypes with properties of both M1 and M2 cells [6], TAMs being a prominent example $[4,5,7,8]$.

Macrophage polarization is regulated by a plethora of signaling molecules and transcriptional regulators. These include the nuclear receptor proliferator-activated receptor $\beta / \delta(\operatorname{PPAR} \beta / \delta)$, a ligand-inducible transcription factor with established functions in intermediary metabolism and immune regulation [9, 10]. The latter has been documented in several reports addressing the role of $\mathrm{PPAR} \beta / \delta$ in inflammatory responses of the skin $[11,12]$ and the M2-like polarization of macrophages in adipose tissue and liver $[13,14]$. PPAR $\beta / \delta$ has also been implicated in tumorigenesis in a number of studies with conflicting results [15], which may be due to divergent functions of the receptor in tumor cells and tumor-associated host cells as well as differences in the experimental models used (mouse strains, synthetic ligands).

PPAR $\beta / \delta$ binds to PPAR response elements (PPREs) at its target genes as a heterodimer with a retinoid $\mathrm{X}$ receptor (RXR), which is activated only upon interaction with an agonistic ligand (canonical regulation) [15]. These include unsaturated fatty acids [16], prostaglandin $\mathrm{I}_{2}$ (prostacyclin) [17], 15-hydroxyeicosatetraenoic acid (15-HETE) [18] and a range of synthetic ligands, originally developed in light of the association of PPAR $\beta / \delta$ with metabolic diseases [15]. Genome-wide analyses have identified PPRE-mediated repression as a major mechanism of transcriptional regulation by unliganded $\operatorname{PPAR} \beta / \delta$, and showed that an agonist-mediated switch induces a subset of these genes [19]. PPRE-mediated repression is enhanced by inverse agonists, such as ST247 [20], which establish a repressor complex that apparently is different from the unliganded receptor complex [21].

$\mathrm{PPAR} \beta / \delta$ can also regulate genes by interacting with specific transcription factors both in a PPRE-dependent [22] and independent fashion [23]. For example, unliganded PPAR $\beta / \delta$ in murine macrophages sequesters BCL6, a transcriptional repressor of inflammatory NFאBregulated genes [23]. PPAR $\beta / \delta$ also modulates $\mathrm{NF \kappa B}$ signaling by other mechanisms, including its interaction with the p65 subunit of NFKB [24-27].

We have recently addressed the function of $\mathrm{PPAR} \beta / \delta$ in normal human macrophages by determining the global PPAR $\beta / \delta$-regulated signaling network in primary monocyte-derived macrophages [28]. Besides canonically regulated genes with metabolic functions, we also identified a number of target genes with immune regulatory functions. These are type-selective and subject to either canonical regulation, such as $C D 1 D$, CD52, CD300A, LRP5, NLRC, or indirect repression by

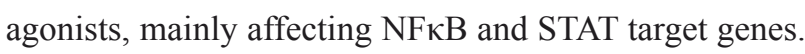
Consistent with these findings, PPAR $\beta / \delta$ agonists triggered hallmarks of an anti-inflammatory phenotype. However, we also identified positive regulatory effects on specific immune modulatory modules, in particular a stimulation of T-cell activation. PPAR $\beta / \delta$ agonists thus induce a unique macrophage activation state with strong antiinflammatory but also specific stimulatory components, suggesting a context-dependent function of PPAR $\beta / \delta$ in immune regulation.

To date, transcriptome data for human TAMs has not been reported. Furthermore, the gene regulatory function of PPAR $\beta / \delta$ in TAMs has not been analyzed. Ovarian cancer is an excellent model to study TAMs, since these cells can be isolated in large quantities from the malignancy-associated peritoneal ascites. These ascites-derived macrophages display a mixed-polarization phenotype expressing both M1 and M2 markers [8]. Consistent with this finding, interpatient polarization differences unrelated to the M1/M2 classification scheme showed a clear association with the clinical outcome [8]. To elucidate the mechanisms underlying the protumorigenic polarization of TAMs in ovarian cancer and the role of PPAR $\beta / \delta$ in this context we determined the $\operatorname{PPAR} \beta / \delta$-regulated transcriptome and PPAR $\beta / \delta$ cistrome in ovarian carcinoma TAMs in comparison to normal human monocyte-derived macrophages (MDMs).

\section{RESULTS}

\section{Ligand-induced cellular alterations in human MDMs}

$\mathrm{CD}_{14}{ }^{+}$cells from human serous ovarian carcinoma ascites (TAMs) rapidly adhere to cell culture dishes and assume a macrophage-like morphology. We used this experimental system to investigate the affects of the synthetic PPAR $\beta / \delta$ agonist L165,041 on freshly isolated TAMs in short-term culture in comparison to normal monocyte-derived macrophages (MDMs). This comparison is conceptually relevant, since TAMs, including ascites-associated macrophages, are derived from blood monocytes [29-32]. Under the experimental conditions used TAMs showed a clearly enhanced expression of $C D 163$ and a very low level of $M M P 9$ mRNA relative to MDMs (Figure 1A), which is consistent with the polarization phenotype of TAMs in vivo [8]. We therefore conclude that our experimental system is suitable to investigate ligand-induced changes in TAMs compared to MDMs.

We have previously described that the synthetic PPAR $\beta / \delta$ agonist L165,041 induces a morphology in MDMs that resembles that of IL-4 treated macrophages [28] (Figure 1B and 1C). TAMs, on the other hand, 
displayed an unchanged morphology upon L165,041 treatment (Figure 1D and 1E). This observation suggests that TAMs are largely unresponsive to exogenous PPAR $\beta / \delta$ ligands. In order to address the mechanistic basis of this observation we performed comprehensive genomewide studies as described below.

\section{Impaired ligand response and upregulation of PPAR $\beta / \delta$ target genes in cultured ovarian carcinoma TAMs}

Ascites-derived adherent macrophages showed a clear accumulation of PPAR $\beta / \delta$ and RXR at the upstream enhancer of the established PPAR $\beta / \delta$ target gene $P D K 4$ $[19,33]$ in vivo (Figure 2A) with a strong enrichment of both factors (30-fold relative to IgG control for PPAR $\beta / \delta$; 40-fold for RXR). This is similar to the enrichment in MDMs (30- and 43-fold, respectively), but much higher compared to monocytes (4- to 5-fold, respectively). These data are therefore consistent with the definition of ascites-derived $\mathrm{CD} 14^{+}$cells as TAMs rather than ascitesassociated monocytes and confirm their suitability for $\operatorname{PPAR} \beta / \delta$ centered genome-wide studies.

Toward this end, MDMs in normal growth medium and freshly isolated TAMs in ascites were exposed to a synthetic PPAR $\beta / \delta$ agonist, inverse PPAR $\beta$ agonists or solvent (DMSO) for 1 day and analyzed by RNA-Seq (Table S2). The specificity of these ligands for PPAR $\beta / \delta$ is illustrated in Figure S1. Only a small number of genes ( $n$ $=30$ ) were found to be induced by the agonist L165,041 in TAMs $(\log \mathrm{FC} \geq 1 ; \mathrm{FPKM} \geq 0.3)$ compared to MDMs ( $n$ $=102)$ with a small intersection $(n=7$; Figure $2 \mathrm{~B}$, top; Figure 2C; Table S3). On the other hand, the number of genes downregulated by the inverse agonists ST247 or PTS264 was considerably greater in TAMs $(n=50)$ relative to MDMs $(n=18)$ with a minor overlap $(n=8$; Figure 2B, bottom; Table S3). These findings would be consistent with the presence of high concentrations of PPAR $\beta / \delta$ agonists in TAMs relative to MDMs.

The observation that the majority of PPAR $\beta / \delta$ target genes were refractory to synthetic agonists was confirmed by RT-qPCR for PDK4 and ANGPTL4 (Figure 2D). Both genes were induced by L165,041 in MDMs $>50$-fold (average; blue symbols), whereas induction in TAMs cultured in ascites (orange symbols) was $<10$-fold (PDK4) or undetectable (ANGPTL4). When TAMs were cultured in R10 for $24 \mathrm{~h}$ instead of ascites, PDK4 induction was only slightly higher (grey symbols). These findings indicate that the loss of ligand regulation in TAMs is not dependent on the continuous presence of ascites, pointing to a relatively stable alteration affecting the regulation of $\mathrm{PPAR} \beta / \delta$ target genes.

We have previously identified canonical PPAR $\beta / \delta$
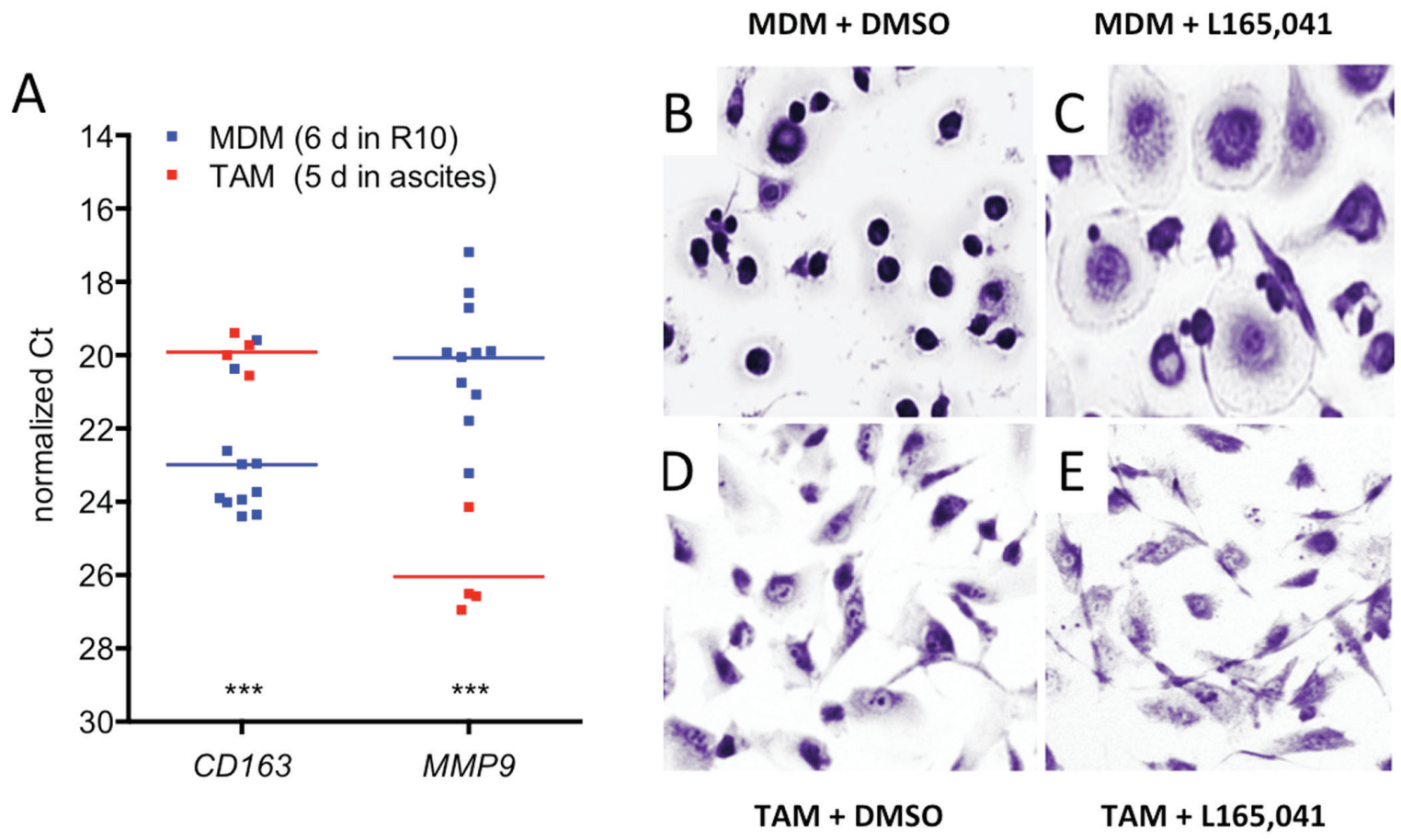

Figure 1: Effects of PPARß/ס ligands on the morphology of human MDMs and ovarian carcinoma TAMs. A. Expression of the macrophage polarization marker genes CD163 and MMP9 in cultured TAMs and MDMs. The data were obtained by RT-qPCR analysis of TAMs (red data points; $n=4$ ) and MDMs (blue: $n=11$ ) from different donors. Horizontal lines show the medians; asterisks indicate statistical significance. B, C. Giemsa staining of human MDMs differentiated in XV0 medium for 8 days in the presence of the PPAR $\beta / \delta$ agonist L165,041 or solvent (DMSO). D, E. TAMs treated with agonist or DMSO as in panel B and C. 
target genes in human MDMs that are agonist-induced and occupied by PPAR $\beta / \delta$-RXR complexes [28]. In combination with the additional RNA-Seq data of the present study, a total of 195 ligand-regulated target genes were identified, defined as "upregulated by agonist versus inverse agonist", 95 of which were associated with PPAR $\beta / \delta$ enrichment sites (Figure 2E; Table S3, columns "L" and "K"). Delineation of the PPAR $\beta / \delta$ cistrome for 3 different patient samples in the present study (Suppl. Table S4) showed that at least 45 of these genomic loci were also occupied by PPAR $\beta / \delta$ in TAMs (Figure $2 \mathrm{E}$; Table S3, column "J"), including those genes showing an altered ligand regulation in TAMs, exemplified by PDK4, CPT1A,
SLC25A20, CD52 and PHACTR1 (Figure 2F).

\section{Deregulation of PPAR $\beta / \delta$ target genes in ovarian carcinoma TAMs in vivo}

We next compared the expression and ligand regulation of PPAR $\beta / \delta$ target genes in ascites-associated macrophages from ten different patients (Table S5) with the set of 195 ligand-regulated target genes in MDMs identified by RNA-Seq analysis of cells from 5 healthy donors (see above; Table S3). Intriguingly, a large fraction of these PPAR $\beta / \delta$ target genes (dark blue dots; $n=54$ )
A

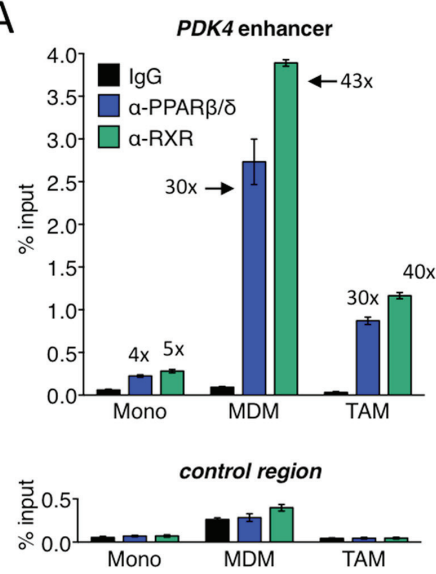

B
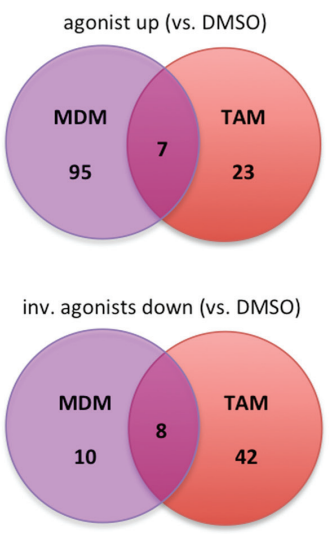

C

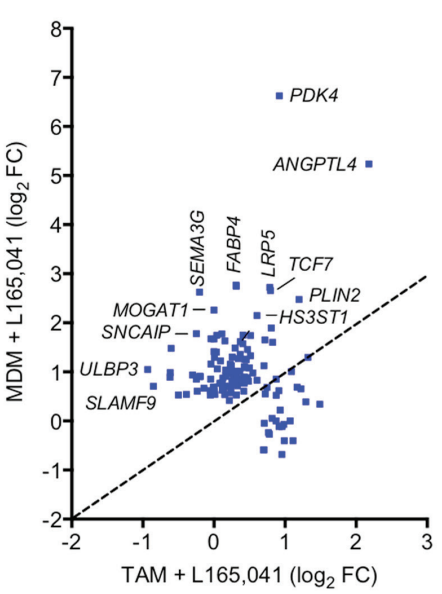

$\mathrm{D}$

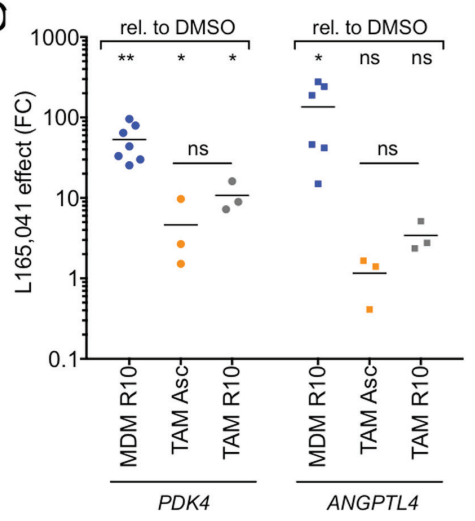

$\mathrm{E}$

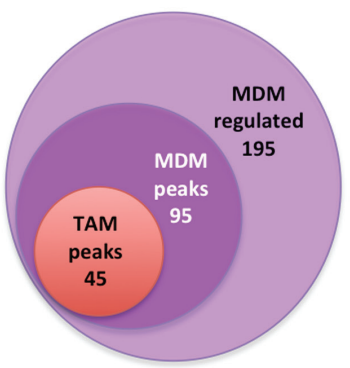

$\mathrm{F}$

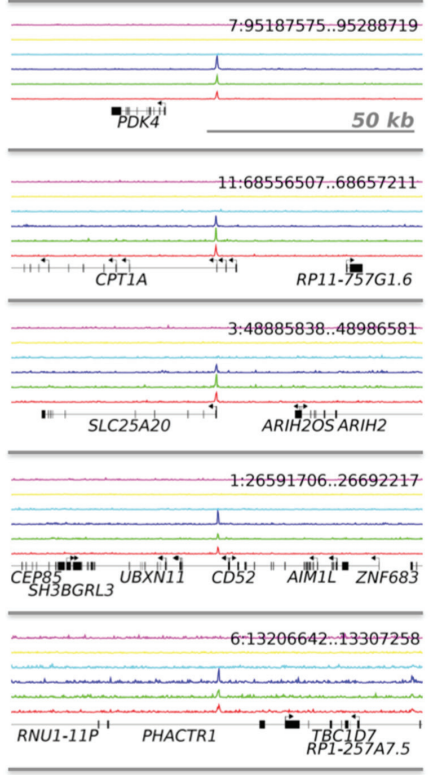

Figure 2: Deregulation of PPAR $\beta / \delta$ target genes in cultured ovarian carcinoma TAMs. A. PPAR $\beta / \delta$ and $R X R$ enrichment at the PDK4 enhancer and an irrelevant control region in human monocytes, MDMs and TAMs (ChIP-qPCR; sample size: 4). B. Venn diagrams of RNA-Seq data showing overlaps of ligand-regulated high-confidence direct target genes in MDMs grown in R10 medium or purified TAMs cultured in ascites for 1 day in the presence of agonist (L165,041), inverse agonist (ST247or PT-S264) or solvent (DMSO). C. Ligand response of PPAR $\beta / \delta$ target genes in TAMs versus MDMs. Data represents the $\log _{2}$ fold change (L165,041 relative to DMS0) calculated from RNA-Seq data. The diagonal line indicates equal regulation in both cell types. D. Expression and ligand response of $P D K 4$ and ANGPTL4 by L165,041 in MDMs in R10 $(n=7)$ and TAMs $(n=3)$ cultured in either ascites or R10 medium. Cells were cultured in the presence of ligand or DMSO for $24 \mathrm{~h}$ and analyzed by RT-qPCR. Data are expressed as fold regulation (FC) relative to DMSO-treated cells. E. Overlap of genes regulated in MDMs (agonist versus inverse agonist), genomic regions with PPAR $\beta / \delta$ binding sites in MDMs and PPAR $\beta / \delta$ enrichment sites in TAMs (ChIP-Seq). F. PPAR $\beta / \delta$ enrichment (ChIP-Seq) at the PDK4, CPT1A, SLC25A20, CD52 and PHACTR1 loci for 3 different TAM samples (bottom 3 lines: dark blue, green, red). The top 3 lanes (magenta, yellow, light blue) represent the corresponding control IgG runs. 


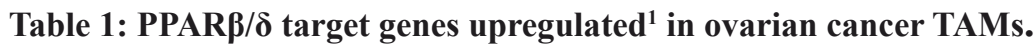

\begin{tabular}{|c|c|c|c|c|}
\hline Gene & Description & $\begin{array}{l}\text { agonist } \\
\operatorname{MDM}(\mathrm{FC})^{2}\end{array}$ & $\begin{array}{r}\text { PPAR } \beta / \delta \\
\text { peak }^{3}\end{array}$ & $\begin{array}{l}\text { refractory in } \\
\text { TAM }^{4}\end{array}$ \\
\hline$A C A D V L$ & acyl-CoA dehydrogenase, very long chain & 3.3 & + & + \\
\hline$A C S S 3$ & acyl-CoA synthetase short-chain family member 3 & 2.3 & - & + \\
\hline AMOTL1 & angiomotin like 1 & 1.9 & - & + \\
\hline ANGPTL4 & angiopoietin-like 4 & 37.8 & + & + \\
\hline$A N K R D 1$ & ankyrin repeat domain 1 (cardiac muscle) & 1.8 & - & - \\
\hline C19orf59 & chromosome 19 open reading frame 59 & 6.7 & + & + \\
\hline Clorf162 & chromosome 1 open reading frame 162 & 2.2 & + & + \\
\hline$C 1 Q C$ & complement component 1 , q subcomponent, $\mathrm{C}$ chain & 1.5 & - & - \\
\hline CABLES1 & Cdk5 and Abl enzyme substrate 1 & 3.2 & - & + \\
\hline$C A C N B 1$ & calcium channel, voltage-dependent, beta 1 subunit & 2.4 & + & + \\
\hline$C D 300 A$ & CD300a molecule & 1.5 & + & - \\
\hline$C L D N D 2$ & claudin domain containing 2 & 2.2 & + & + \\
\hline$C P T 1 A$ & carnitine palmitoyltransferase 1A (liver) & 3.4 & + & + \\
\hline CXorf21 & chromosome $\mathrm{X}$ open reading frame 21 & 1.8 & + & + \\
\hline$D L G 4$ & discs, large homolog 4 (Drosophila) & 1.6 & + & + \\
\hline$F A M 3 B$ & family with sequence similarity 3 , member B & 2.7 & - & + \\
\hline$F C G R 3 A$ & Fc fragment of IgG, low affinity IIIa, receptor (CD16a) & 1.5 & + & - \\
\hline$F C G R T$ & Fc fragment of IgG, receptor, transporter, alpha & 1.5 & + & - \\
\hline FOS & FBJ murine osteosarcoma viral oncogene homolog & 1.1 & + & - \\
\hline$G P A 33$ & glycoprotein A33 (transmembrane) & 1.8 & - & + \\
\hline$H M O X 1$ & heme oxygenase (decycling) 1 & 1.3 & + & - \\
\hline$H P$ & haptoglobin & 2.2 & - & - \\
\hline$H P R$ & haptoglobin-related protein & 2.6 & - & - \\
\hline$H S 3 S T 1$ & heparan sulfate (glucosamine) 3-O-sulfotransferase 1 & 4.4 & - & + \\
\hline IL27 & interleukin 27 & 1.2 & - & - \\
\hline$I M P A 2$ & inositol(myo)-1(or 4)-monophosphatase 2 & 2.6 & + & + \\
\hline$I N F 2$ & inverted formin, $\mathrm{FH} 2$ and $\mathrm{WH} 2$ domain containing & 1.5 & - & + \\
\hline KBTBD11 & kelch repeat and $\mathrm{BTB}(\mathrm{POZ})$ domain containing 11 & 1.3 & - & - \\
\hline$K L F 11$ & Kruppel-like factor 11 & 1.4 & - & - \\
\hline KRT4 & keratin 4 & 1.9 & - & + \\
\hline LRP5 & low density lipoprotein receptor-related protein 5 & 6.6 & + & + \\
\hline$M A C C 1$ & metastasis associated in colon cancer 1 & 1.8 & + & - \\
\hline$M A P 3 K 8$ & mitogen-activated protein kinase kinase kinase 8 & 1.5 & - & + \\
\hline$M E G F 9$ & multiple EGF-like-domains 9 & 1.5 & + & - \\
\hline$M S 4 A 14$ & membrane-spanning 4-domains, subfam. A, member 14 & 1.6 & - & + \\
\hline$M S 4 A 7$ & membrane-spanning 4-domains, subfamily A, member 7 & 1.6 & - & - \\
\hline
\end{tabular}




\begin{tabular}{|l|l|l|l|l|}
\hline PCOLCE2 & procollagen C-endopeptidase enhancer 2 & 1.9 & \multicolumn{1}{|c|}{-} & - \\
\hline PDE1B & phosphodiesterase 1B, calmodulin-dependent & 2.2 & - & - \\
\hline PDK4 & pyruvate dehydrogenase kinase 4 & 99.0 & + & + \\
\hline PHACTR1 & phosphatase and actin regulator 1 & 3.1 & + & + \\
\hline PLIN2 & perilipin 2 & 5.5 & + & + \\
\hline PPP1R15B & protein phosphatase 1, regulatory subunit 15B & 1.6 & + & - \\
\hline RBP7 & retinol binding protein 7, cellular & 1.8 & - & + \\
\hline RCN3 & reticulocalbin 3, EF-hand calcium binding domain & 2.6 & + & + \\
\hline RETN & resistin & 1.3 & + & + \\
\hline SI00Z & S100 calcium binding protein Z & 3.1 & + & - \\
\hline SIPA1L2 & signal-induced proliferation-associated 1 like 2 & 2.1 & + & + \\
\hline ST14 & suppression of tumorigenicity 14 (colon carcinoma) & 2.4 & + & + \\
\hline TCF7 & transcription factor 7 (T-cell specific, HMG-box) & 6.3 & + & + \\
\hline TMEM150B & transmembrane protein 150B & 1.2 & + & - \\
\hline TMEM37 & transmembrane protein 37 & 1.7 & + & + \\
\hline TRIM14 & tripartite motif containing 14 & 1.6 & - & + \\
\hline TSKS & testis-specific serine kinase substrate & 0.8 & + & - \\
\hline VSIG10L & V-set and immunoglobulin domain containing 10 like & 1.4 & + & - \\
\hline
\end{tabular}

${ }^{1}$ LogFC TAMs in vivo vs MDMs $>0.7$ (Figures 4A and 4B; Tables S3, S5)

${ }^{2}$ Ratio FPKM L165,041 / FPKM DMSO in MDMs (Figure 2B; Table S2)

${ }^{3}$ Peak in MDMs or TAMs: ChIP-Seq data (Figures 2E ad 2F; Table S4; Adhikary et al., 2015)

${ }^{4}$ Refractory to synthetic agonist in TAMs (Figure 3C; Table S3); $<2.0$-fold (Fig. 2D, 4A, 4C; Table S2)

were upregulated $\left(\log _{2} \mathrm{FC} \geq 0.7\right)$ in freshly isolated TAMs relative to MDMs (Figure 3A). Approximately half of the genes upregulated in cultured TAMs (21/40) overlapped with the genes upregulated in vivo (Figure 3B; Table S3), thus validating the results obtained in vitro. Most of the genes upregulated in TAMs were also refractory to regulation by a synthetic agonist $(n=32$; Figure 3 C; Table S3), suggesting a link between upregulation and loss of ligand regulation. A summary of these data is shown in Table 1.

Comparison of the expression levels of three PPAR $\beta / \delta$ target genes, PDK4, ANGPTL4 and CPT1A in TAMs from 12 patients and MDMs from 12 healthy donors confirmed this result (Figure 3D). As shown for PDK4, deregulation of gene expression in TAMs correlated with increased protein levels, which, in contrast to MDMs, were largely insensitive to ligand stimulation (Figure 3E).

Interestingly, we also found a number of PPAR $\beta / \delta$ target genes downregulated in TAMs relative to MDMs, for example $F A B P 4$ and $A B C G 2$ (Figure 3A; cyan data points). Ovarian cancer is known to consist of a plethora of signaling mediators, including cytokines [8] and lipids (see data below). It is therefore likely that a subset of target genes is downregulated by repressive signaling pathways triggered by specific components of the ovarian cancer microenvironment, thereby preventing their potential stimulation analogous to the PPAR $\beta / \delta$ target genes discussed in the preceding paragraph.

The deregulation of ANGPTL4 is of particular interest, since its secreted product has been associated with cancer cell invasion and metastasis and is present in substantial amounts in the malignancy-associated ascites of most serous ovarian carcinoma patients (Figure 3F). We therefore tested the Cancer Genome Atlas (TCGA) cohort of 506 high grade serous ovarian cancer patients [34] for a potential link of ANGPTL4 expression to the clinical outcome of the disease. As depicted by the Kaplan-Meier plot in Figure 3G, ANGPTL4 levels showed a significant inverse association with relapse-free survival (RFS) [p $=0.0154$; hazard ratio $=1.38$ (1.06-1.79); median RFS: 15.63 versus 19.8 months].

Annotation of all PPAR $\beta / \delta$ target genes constitutively upregulated in TAMs by Ingenuity Pathway Analysis (IPA) identified metabolism (glucose, lipid), inflammation, cell migration and survival as top functions (Figure 4A). As expected, the PPAR ligands (benzafibrate, EPA, rosiglitazone, pirinixic acid) were found among the top upstream regulators (Figure 4B). The presence of the pro-inflammatory mediator LPS in this list is consistent with the results obtained by the functional annotation analysis (inflammation). 


\section{Deregulation of PPAR $\beta / \delta$ target genes by soluble mediators in malignancy-associated ascites}

The data in Figure 2 suggests that the unaltered occupancy of direct target genes by PPAR $\beta / \delta$-RXR in conjunction with a TAM-specific mechanism activating these chromatin-bound complexes is responsible for their deregulation in TAMs. One explanation for this deregulation could be the presence of ascites-associated activators of PPAR $\beta / \delta$. We addressed this question by testing the effect of cell-free ascites samples on the regulation of PPAR $\beta / \delta$ target genes in MDMs. Figure $5 \mathrm{~A}$ shows a clear upregulation of the target genes PDK4, CPT1A, ANGPTL4, LRP5 and CD300A by two different ascites samples, which in several cases reached the level of L165,041 induction (Figure 5B; blue dots). Furthermore, induction of all 5 genes by L165,041 was severely diminished in the presence of ascites (Figure 5B; orange dots).

Therefore, we sought to investigate whether deregulation of target genes by ascites might be attributable to the activation of PPAR $\beta / \delta$, and thus dependent on PPAR $\beta / \delta$ binding sites (PPREs) in these genes. It has previously been shown that an upstream enhancer with three contiguous PPREs mediates induction of $P D K 4$ by PPAR $\beta / \delta$ ligands [19]. A luciferase construct with a genomic $1.5 \mathrm{~kb}$ fragment encompassing this enhancer showed a dramatic upregulation by three

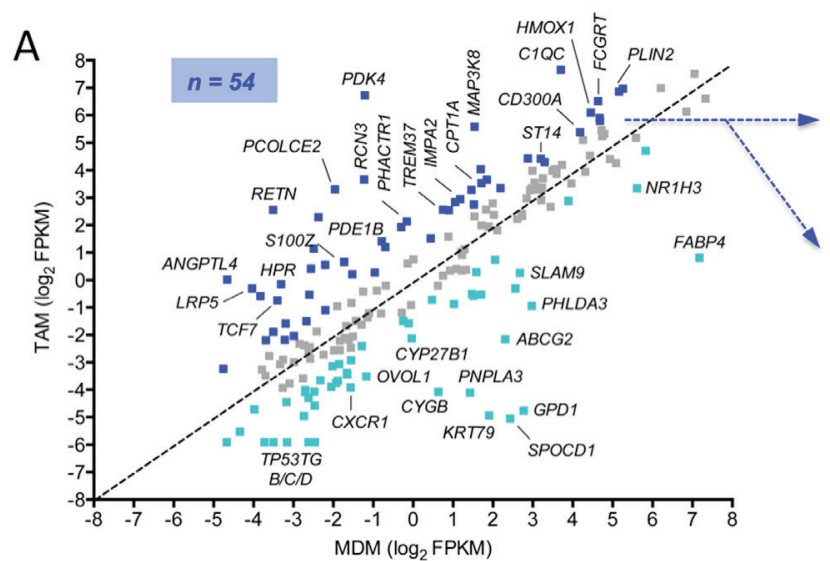

E

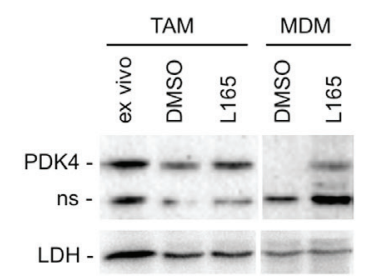

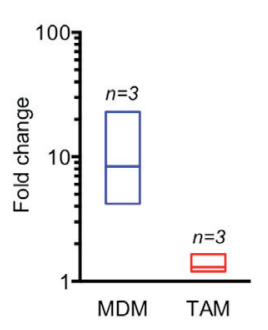

$\mathrm{F}$

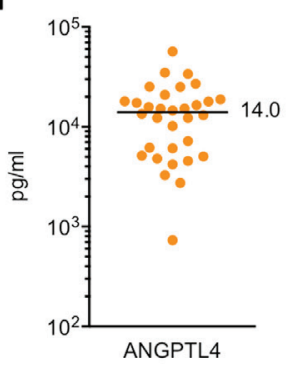

B

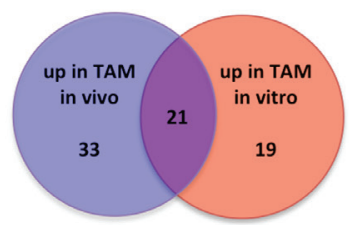

C

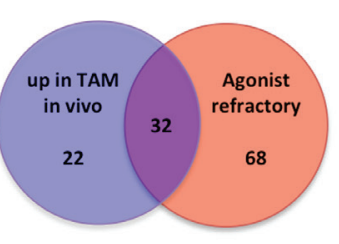

G

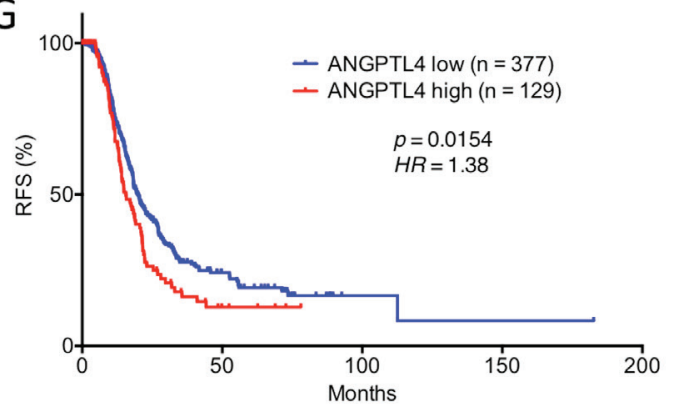

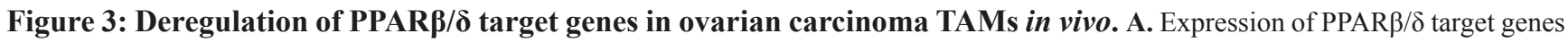
(median FPKM values) in freshly isolated TAMs (median of 10 samples) versus MDMs (5 samples). The diagonal line indicates equal levels in both cell types. Blue dots: upregulation in TAMs $\geq 2$-fold; cyan dots: downregulation $\geq 2$-fold in TAMs; grey dots: no change. B. Overlap of PPAR $\beta / \delta$ target genes upregulated in freshly isolated TAMs versus MDMs (blue dots in A) and in cultured TAMs (experimental setup as in Figure 2). C. Overlap of PPAR $\beta / \delta$ target genes upregulated in TAMs versus MDMs (blue dots in A) and target genes refractory to synthetic agonists in TAMs (data from Figure 2B). D. RT-qPCR analysis of PDK4, ANGPTL4 and CPT1A mRNA expression levels in freshly isolated TAMs and MDMs from ovarian cancer patients $(n=12)$ and healthy donors $(n=12)$, respectively. Horizontal bars indicate the median. Statistical significance was tested between the respective TAM and MDM groups. E. Immunoblot analysis of PDK4 protein induction by PPAR $\beta / \delta$ agonist in MDMs and TAMs. The figure shows representative immunoblots (including PPAR $\beta / \delta$ and LDH as the loading control) for both cell types and a quantitative evaluation of biological replicates with TAMs from 3 different patients and MDMs from 3 donors. Cells were exposed to ligands for $1 \mathrm{~d}$ in R10 medium; TAMs were also analyzed directly after isolation ("ex vivo"). Signal intensities were quantified and standardized to LDH. The diagram on the right depicts the induction by L165,041 (fold change) in TAMs and MDMs in vitro; boxes show the ranges of inducibility and the median for each group of samples. Induction values for MDMs represent estimations due to the extremely low basal level of PDK4 in MDMs. The $\alpha$-PDK4 antibody was validated as shown in Figure S2. n.s., nonspecific band. F. Concentrations of ANGPTL4 protein in the ascites of serous ovarian carcinoma patients $(n=32)$ determined by ELISA. The horizontal line indicated the median. G. Meier-Kaplan plot showing a correlation of high ANGPTL4 expression with the relapse-free survival of high grade serous ovarian carcinoma patients of the TCGA cohort ( $n=377$ in ANGPTL4 high group; $n=129$ ANGPTL4 low) [62]. 
different ascites samples (Figure 5C). These effects were clearly PPRE-dependent, since the mutation of 1,2 or 3 sites gradually abrogated the induction of luciferase activity by ascites (Figure $5 \mathrm{C}$ ).

We found that PPAR $\beta / \delta$ target genes are inducible by ascites in murine bone marrow-derived macrophages (BMDMs), similar to human MDMs. We were therefore able to show that the observed target gene deregulation was dependent on functional PPAR $\beta / \delta$. Ascites upregulated the Pdk4 and Angptl4 genes and abrogated their induction by L165,041 in wild-type BMDMs, whereas no significant ascites effect was detected on PDK4 in cells with disrupted Ppard alleles (Figure 5D). Likewise, the ascites-mediated induction of ANGPTL4 was either absent (Asc69) or strongly reduced (Asc78) in Ppard null cells. These observations indicate that PPAR $\beta / \delta$ is responsible for the deregulation of $\mathrm{PPAR} \beta / \delta$ target genes by ascites, even though a minor contribution by other PPAR subtypes cannot be unequivocally ruled out. ANGPTL4 is induced by a plethora of signaling pathways [35], which presumably explains the residual induction by Asc78 in Ppard null cells.

\section{Endogenous agonists present in ovarian carcinoma ascites deregulate PPAR $\beta / \delta$ target genes in MDMs}

The results described above suggest that ovarian cancer associated ascites might contain high levels of endogenous PPAR $\beta / \delta$ agonists. Since all known PPAR $\beta / \delta$ agonists are fatty acids or fatty acid derivatives, we performed a systematic lipidomic analysis of 97 molecules in 38 different ascites samples by LC-MS/MS (Suppl. Table S6). This analysis revealed consistently very high concentrations of several polyunsaturated fatty acids (PUFAs) known as PPAR $\beta / \delta$ agonists [16], with the highest levels observed with linoleic acid (LA) (Figure $6 \mathrm{~A})$. The median concentration for LA was $\sim 50 \mu \mathrm{g} /$ $\mathrm{ml}(\sim 180 \mu \mathrm{M})$, which is far above the described $\mathrm{IC}_{50}$ of $0.75 \mu \mathrm{M}$ for PPAR $\beta / \delta$ binding [16]. This also applies to arachidonic acid (AA) and docosahexaenoic acid (DHA) with median ascites concentrations around $10 \mu \mathrm{g} / \mathrm{ml}$ (Figure 6A).

Addition of AA, LA or DHA to MDM cultures at a concentration of $20 \mu \mathrm{M}$ for $24 \mathrm{~h}$ resulted in a strong induction of the PDK4 gene, while eicosapentaenoic acid (EPA) and $\alpha$-linolenic acid (ALA) had only very modest effects (Figure 6B). PDK4 induction by LA was dose-dependent and rapid with a nearly 10-fold induction

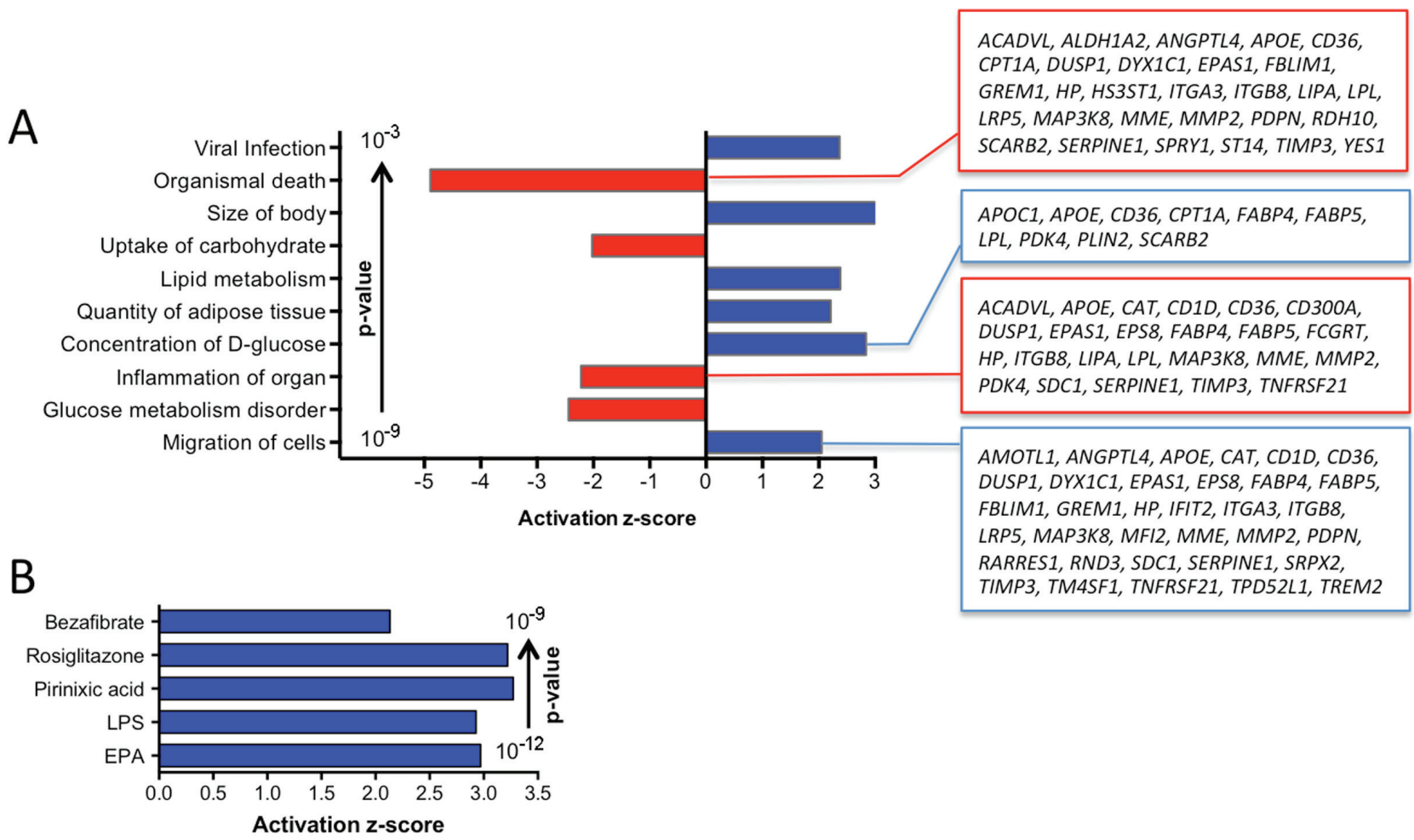

Figure 4: Pathway analyses of PPARß/ס target genes constitutively upregulated in TAMs. A. IPA Diseases and Functions Annotation (functionally different clusters with lowest p-values and highest z-scores). Gene names are shown for the clusters with the largest number of genes. B. IPA Upstream Regulator Analysis (5 top regulators by p-value; z-score $>2$ ). 
already after $3 \mathrm{~h}$ (Figure 6C). Similar results were obtained with the conjugated LAs $9(\mathrm{Z}), 11(\mathrm{E}) \mathrm{LA}$ and $10(\mathrm{Z}), 12(\mathrm{E})$ LA (Figure 6C). LA also potently induced other direct $\mathrm{PPAR} \beta / \delta$ target genes, and this induction was close, or even equal, to activation by L165,041, as shown for PDK4, CPT1A, PLIN2, SLC25A20, ANGPTL4, LRP5 and $C D 300 A$ in Figure 6D.

A number of PPAR $\beta / \delta$ target genes deregulated by ovarian cancer ascites have functions in oncogenesis and immune regulation. It was therefore of great interest to investigate whether their overexpression could be reverted by inverse PPAR $\beta / \delta$ agonists in spite of the high concentrations of agonists in ascites. As shown in Figure $6 \mathrm{E}$, treatment of MDMs cultured in ascites with increasing concentrations of PT-S264 for $24 \mathrm{~h}$ led to progressively lower levels of PDK4 mRNA expression. At the highest tested concentration $(20 \mu \mathrm{M})$, expression was reduced to less than 5\%. Likewise, CPT1A, SLC25A20, LRP5 and $A N G P T L 4$ mRNA expression was reduced to basal levels by PT-S264, with LRP5 and ANGPTL4 being strongly repressed already at concentrations of $1 \mu \mathrm{M}$. These results clearly indicate that inverse agonists are suitable to counteract the deregulation of PPAR $\beta / \delta$ target genes in ovarian carcinoma TAMs.

We also found two other endogenous PPAR $\beta / \delta$ agonists, 15-HETE [18] and 6-keto-prostglandin $\mathrm{F}_{1 \alpha}$ $\left(6-\mathrm{kPGF}_{1 \alpha}\right)$, the stable degradation product of prostacyclin $[17,36]$ in all ascites samples (Figure 6F). Both, 6-kPGF ${ }_{1 \alpha}$ and 15-HETE were found at median levels of $\sim 10 \mathrm{ng} / \mathrm{ml}$ $(\sim 30 \mathrm{nM})$, which corresponds to approximately $3 \%$ of the $\mathrm{IC}_{50}$ concentrations required for PPAR $\beta / \delta$ activation $[18$, 36]. Both metabolites are therefore unlikely to play a role in the deregulation of PPAR $\beta / \delta$ target genes in TAMs.

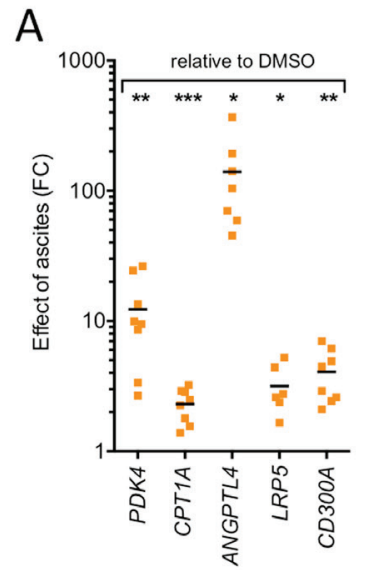

C

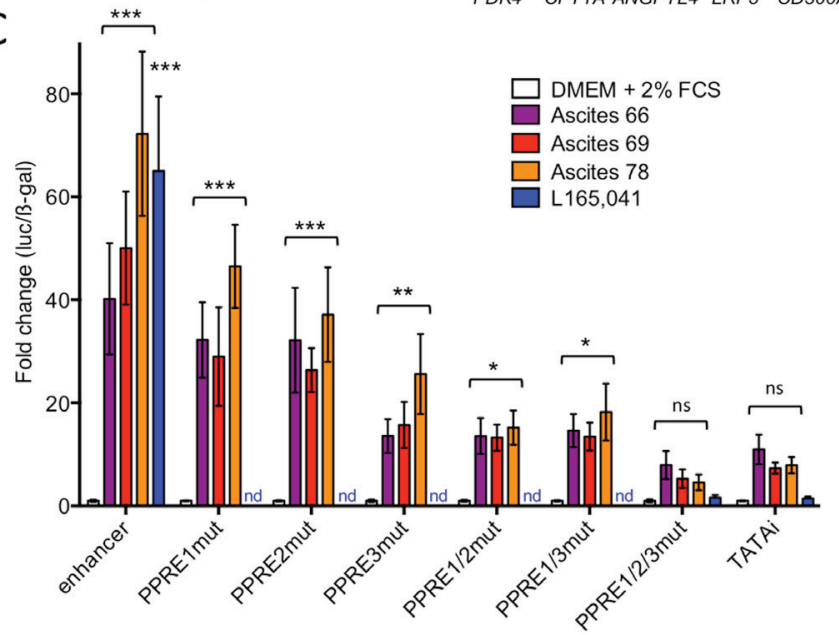

B
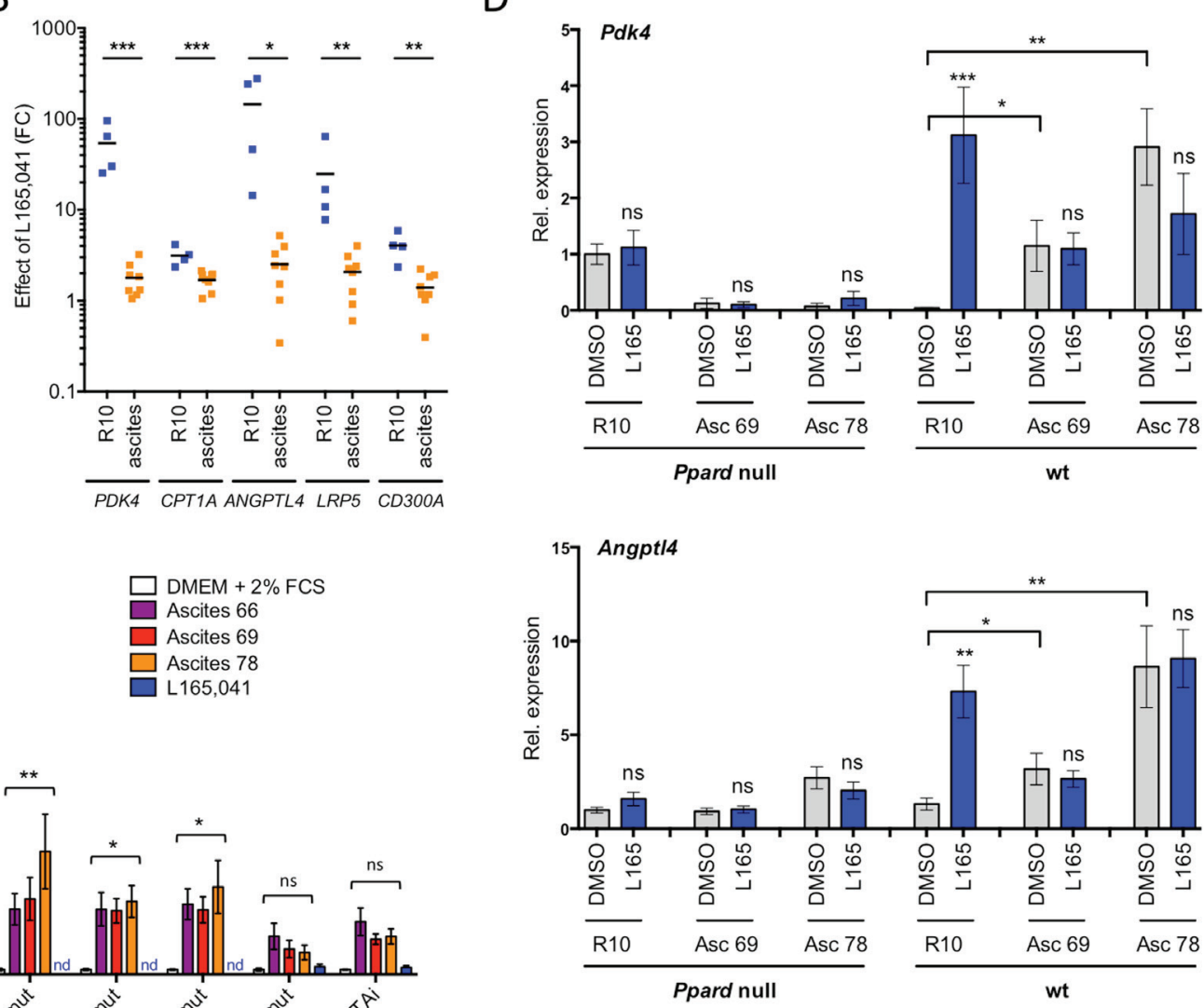

Figure 5: Ascites deregulates PPAR $\beta / \delta$ target genes in normal macrophages and in a PPAR $\beta / \delta$-dependent fashion. A. Upregulation of PPAR $\beta / \delta$ target genes by ascites in MDMs $(n=8 ; 4$ different MDM samples; 2 different ascites samples). RT-qPCR data are expressed as fold change (FC) relative to MDMs R10 medium. B. Regulation of target genes by L165,041 in MDMs $(n=4)$ in R10 or ascites (2 different samples). Data indicate FC relative to DMSO-treated cells. C. PPRE-dependent induction of a PDK4 enhancerluciferase construct in transiently transfected HEY cells $(n=3)$. Constructs were mutated in either 1, 2 or all 3 PPREs, as indicated. Data were normalized to $\beta$-galactosidase activity from a co-transfected CMV- $\beta$-gal expression vector. D. Response of the direct PPAR $\beta / \delta$ target genes Pdk4 and Angptl4 to two different ascites samples and L165,041 in bone marrow-derived macrophages from wild-type and Ppard null mice (sample size: 3 each). Statistical significance was tested for induction by ascites relative to DMSO-treated cells in C and D (asterisks/ns above square brackets) and for induction by L165,041 or in D (asterisks/ns above blue bars). 


\section{Fatty acid accumulation in lipid droplets correlates with transcriptional deregulation}

The data in Figure 2D showed that ligand regulation in TAMs can only be partially restored by culturing the cells in normal cell culture medium. Since macrophages have a propensity to accumulate intracellular lipids, which is enhanced by PPAR $\beta / \delta$ [37], we tested this for ovarian carcinoma TAMs. As shown by staining with the fluorescent dye Nile Red, ascites-derived TAMs harbor a huge amount of lipid droplets, which remains basically unchanged upon culturing these cells in normal growth medium for 4 days (Figure 7A, 7B). The stability of lipid droplets correlated with a compromised ligand regulation of the PPAR $\beta / \delta$ target gene $P D K 4$ (Figure 7C). Consistent with this finding, MDMs rapidly accumulate lipid droplets when exposed to LA at a high level found in ascites, which persisted upon withdrawal of the fatty acids (Figure 7D, 7E), concomitantly with an impaired inducibility by synthetic ligands (Figure 7F). It is therefore likely that internalization of PUFAs from the tumor microenvironment generates a reservoir of agonists contributing to a stable upregulation of PPAR $\beta / \delta$ target genes.

\section{DISCUSSION}

$\operatorname{PPAR} \beta / \delta$ regulates a large group of genes with functions in intermediary metabolism, inflammation and tumor progression, which are coordinately upregulated in TAMs by PUFA ligands present at high concentrations in the ascites of ovarian cancer patients (Table 1). Functional annotation analyses showed that these genes are not only associated with cell type-independent roles in energy production, fatty acid oxidation and lipid storage, but also figure in inflammation, cell migration and cell survival. Upregulation of several of these genes in TAMs is compatible with the pro-tumorigenic role of TAMs and may serve not only to skew TAM polarization but may
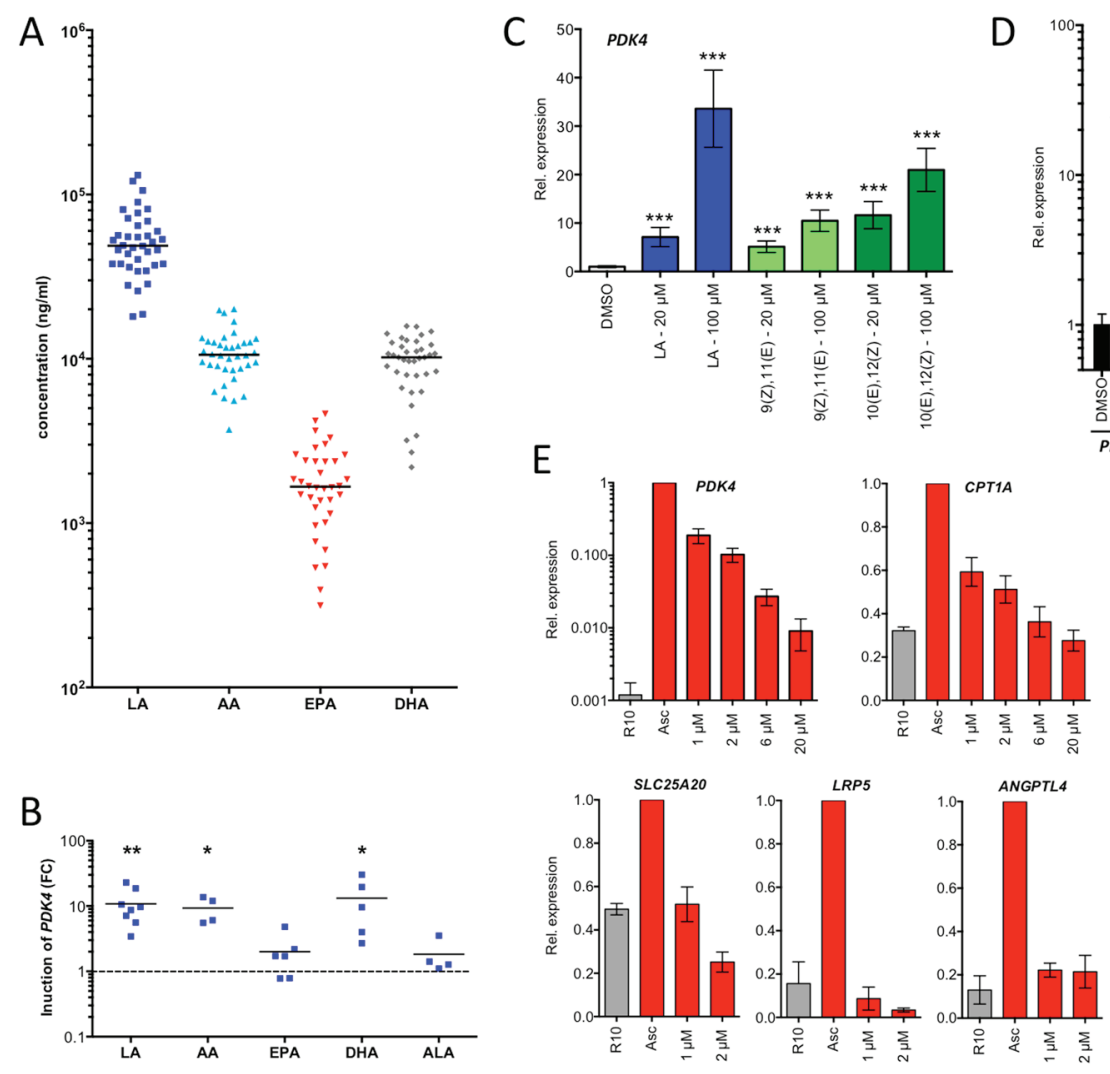
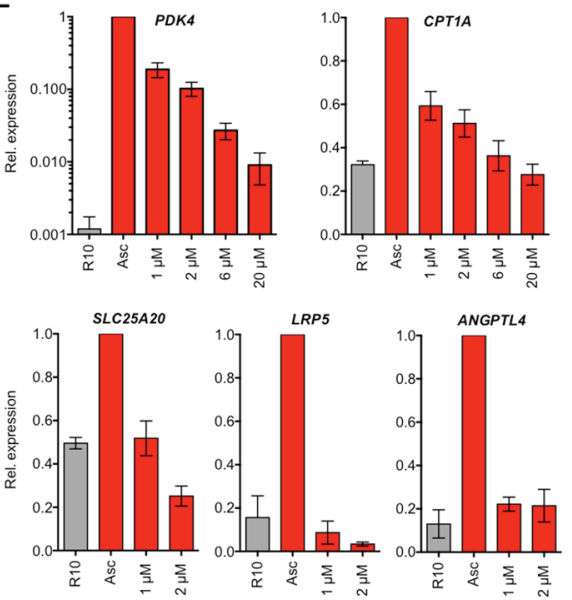
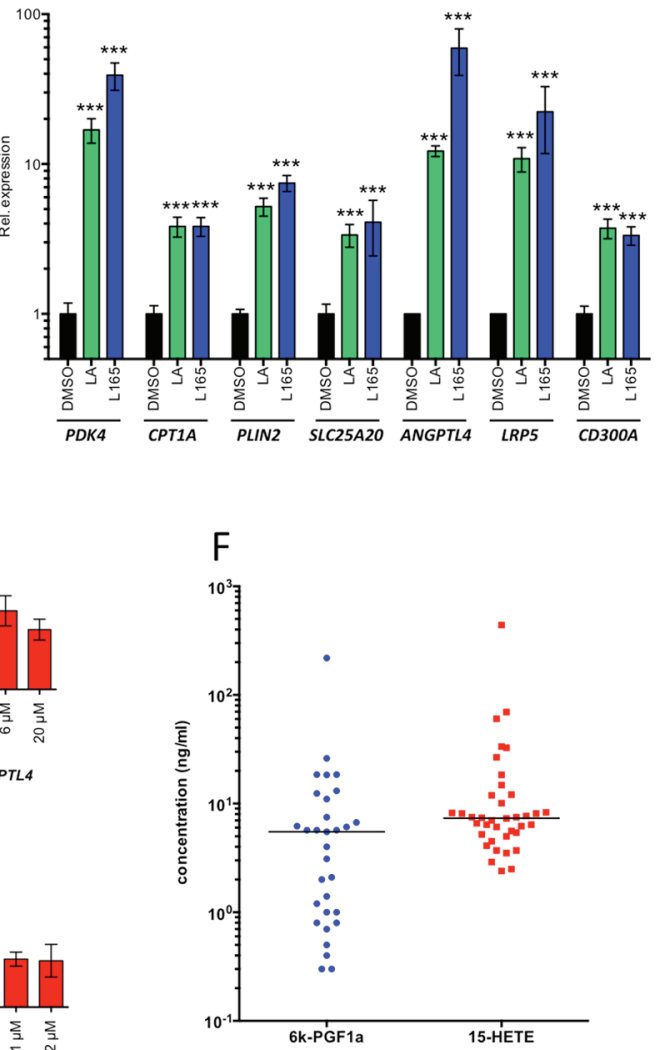

Figure 6: PPAR $\beta / \delta$ ligands are present in ascites at high concentrations and induce PPAR $\beta / \delta$ target genes. A. LC-MS/ MS analysis of polyunsaturated fatty acids (PUFAs) in ascites from ovarian carcinoma patients $(n=38)$. B. Induction of $P D K 4$ in MDMs after $24 \mathrm{~h}$ exposure to different PUFAs in different donors $(n=4-8)$. Each data point represents a biological replicate. C. Rapid induction ( $3 \mathrm{~h}$ stimulus) of PDK4 by LA and conjugated 9(Z),11(E)-LA and 10(Z),12(E)-LA in MDMs (triplicates). D. Induction of PPAR $\beta / \delta$ target genes in MDMs after $24 \mathrm{~h}$ exposure to linoleic acid (LA) in comparison to L165,041 (triplicates). E. Repression of PPAR $\beta / \delta$ target genes in MDMs $(n=3)$ cultured in ascites for $48 \mathrm{~h}$ by different concentrations of PT-S264 added during for the last $24 \mathrm{~h}$ of the experiment. Values were normalized to 1 for cells in ascites. F. LC-MS analysis of 15-HETE and the stable prostacyclin derivative $6 \mathrm{k}$-PGF1 $\alpha$ in the same samples as in A. Horizontal bars show the medians in panels A and B. Values represent averages of triplicate measurements \pm standard deviation in all panels. Significance was tested relative to control cells. 
also directly promote tumor progression, for instance via the secretion of soluble mediators, such as ANGPTL4. We therefore propose that the deregulation of PPAR $\beta / \delta$ target genes by mediators of the tumor environment acts in conjunction with other signaling mechanisms to effect the pro-tumorigenic conversion of host-derived monocytic cells.

\section{Fatty acid PPAR $\beta / \delta$ ligands in ascites}

Several PUFAs known to act as PPAR $\beta / \delta$ agonists were found in all ascites samples tested at levels exceeding the concentrations required for maximal $\operatorname{PPAR} \beta / \delta$ activation, in particular LA, but also arachidonic acid and docosahexaenoic acid [16]. High levels of lipoprotein complexes in ovarian cancer ascites have been described in a previous study, but their fatty acid composition was not determined [38]. Another report suggests the mobilization of LA from omentum in ovarian cancer patients [39], consistent with the very high levels of this fatty acid in the malignancy-associated ascites found in the present study. Several studies also indicate that fatty acids are relevant to the biology and clinical outcome of ovarian cancer. Thus, the increased expression of the fatty acid synthase gene $(F A S)$ predicts shorter survival [40], dietary fat intake and altered lipid metabolism are linked to ovarian cancer risk [41] and in a mouse model tumor growth and invasion are fueled by direct transfer of lipids from omental adipocytes to ovarian cancer with a key role for fatty acid-binding protein 4 [42].

Blood plasma also contains high concentrations of PUFAs [43], yet PPAR $\beta / \delta$ target genes are expressed at low levels in blood monocytes, which is presumably

A
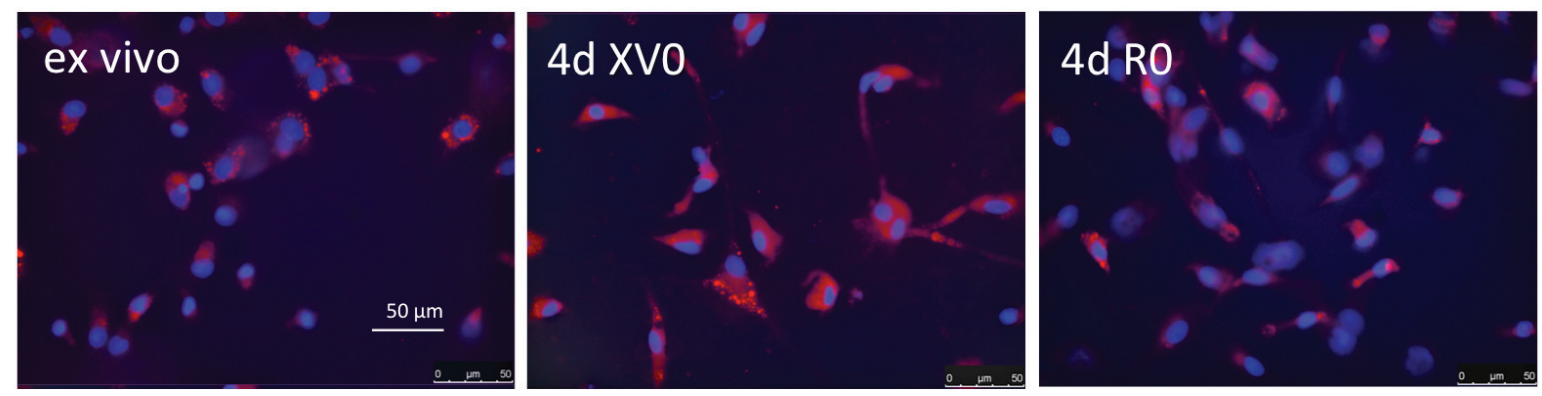

B
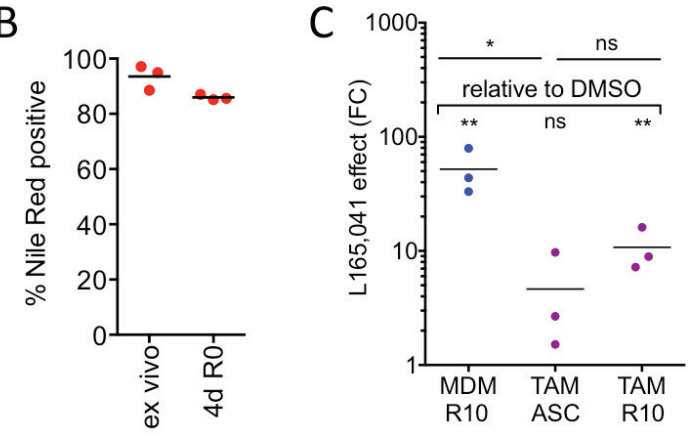

$\mathrm{E}$

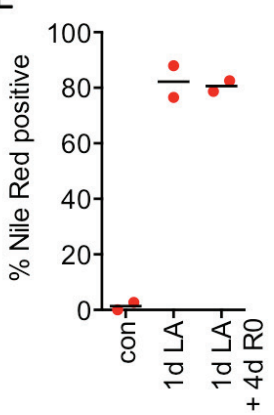

$\mathrm{F}$

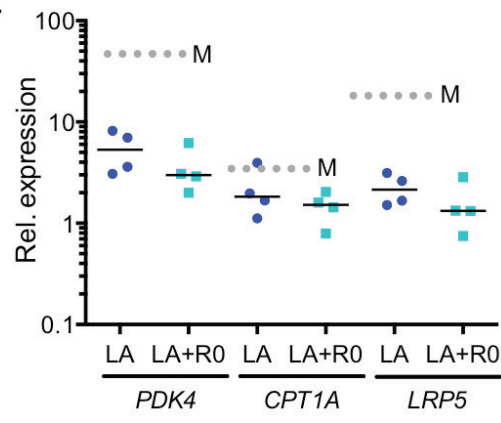

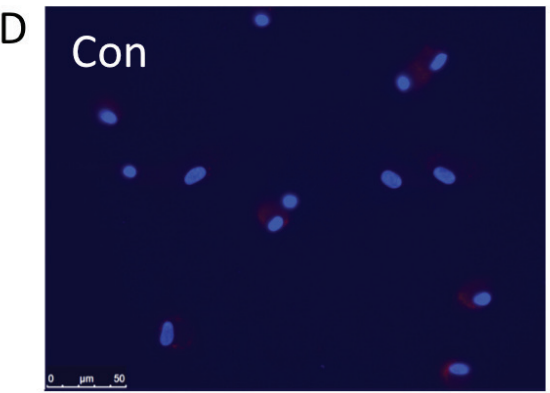
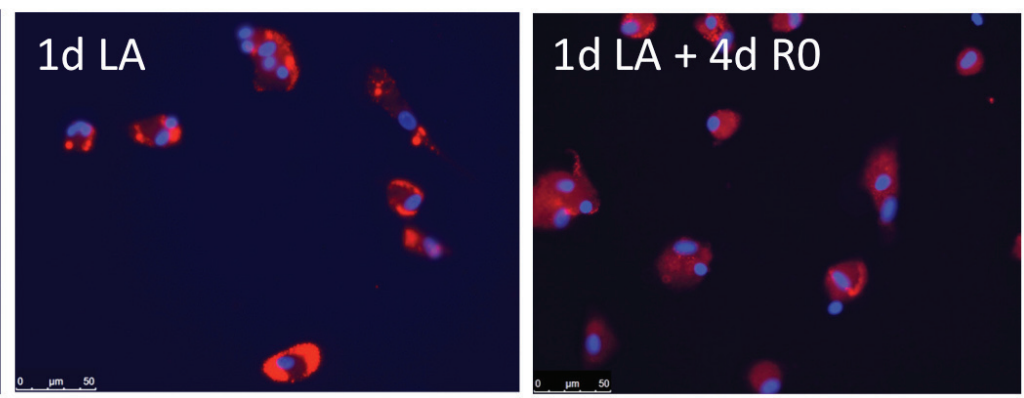

Figure 7: Association of the stable accumulation of lipid droplets in TAMs with the deregulation of the PPARß/ס target gene PDK4. A. Staining of primary TAMs with Nile Red $0 \mathrm{~h}$ (ex vivo) and $4 \mathrm{~d}$ after plating in serum-free XV0 or R0 medium. B. Quantification of Nile Red stained TAMs $(n=3)$ treated as in A. C. L165,041 induction of PDK4 in MDMs $(n=3)$ and in TAMs $(n=3)$ cultured for 4d in ascites or R10 medium. D. Staining of MDMs with Nile Red before (d0) and after a 24-hour exposure to LA (d1), followed by a 4d fatty acid withdrawal in serum-free R0 medium $(\mathrm{d} 1+4)$. E. Quantification of Nile Red stained MDMs $(n=2)$ before and after LA exposure as in D. F. L165,041 induction of PPAR $\beta / \delta$ target genes in MDMs $(n=4)$ pretreated with LA for $1 \mathrm{~d}$, followed by a $4 \mathrm{~d}$ serum-free R0 medium lacking fatty acids. 
due to the low level of PPAR $\beta / \delta$ expression in monocytes (Figure 2A and [28]), at least in part. TAMs represent a special situation in that these cells express $\operatorname{PPAR} \beta / \delta$ at readily detectable levels and at the same time are exposed to high levels of ligands in the tumor microenvironment. Our findings also suggest that PPAR $\beta / \delta$ may serve as a marker to distinguish monocytes from macrophages, and also support the conclusion that ascites-associated CD14 cells are macrophages rather than monocytes.

\section{Deregulated PPAR $\beta / \delta$ target genes in TAMs}

The target gene ANGPTL4 $[44,45]$ is of particular interest in the context of the present study, since it not only figures in lipid metabolism as a regulator of lipoprotein lipase, but also plays an apparently essential role in tumor progression [46]. Thus, ANGPTL4 secreted by tumor cells in response to TGF- $\beta$ and released into the circulation increases the permeability of lung capillaries and facilitates the extravasation of disseminated breast cancer cells in a mouse model [35]. Furthermore, ANGPTL4 increases cancer cell invasion [21] and is part of gene expression signatures associated with distant metastasis in human cancer patients $[35,47]$. ANGPTL4 also inhibits anoikis, which is essential for the survival of circulating tumor cells [48]. Consistent with these observations, several oncogenic signaling pathways converge on the ANGPTL4 gene, including TGF $\beta[21,35,45]$ and AP1 [45].

Deregulated PPAR $\beta / \delta$ target genes with potential roles in macrophage regulation are CD300A and $F O S$. CD300A is a membrane glycoprotein with antiinflammatory functions. For example, deletion of the Cd300a gene in mice has been shown to result in proinflammatory activation of peritoneal macrophages [49], suggesting that its upregulation in TAMs has an immune suppressive effect. On the other hand, FOS has been strongly associated with the pro-inflammatory activation of macrophages [50]. These observations are compatible with a role of deregulated $\operatorname{PPAR} \beta / \delta$ target genes in mediating the mixed-polarization phenotype of TAMs [4, $5,7,8]$.

Several other novel PPAR $\beta / \delta$ target genes upregulated in TAMs potentially play a role in promoting macrophage migration. i.e., PHACTR1 (phosphatase and actin regulator 1), MACC1 and ST14. PHACTR1 plays a role in the G-actin mediated control of actomyosin assembly [51], MACC1 is a transcriptional activator of MET (HGF receptor) and acts as a key regulator of cell motility [52], and ST14/epithin is a protease transcriptionally induced in macrophages by proinflammatory pathways to mediate transendothelial migration [53].

Another PPAR $\beta / \delta$ target gene upregulated in TAMs is LRP5. Its product LRP5 acts as a Frizzled co-receptor and activator of Wnt signaling [54]. In macrophages,
LRP5 is involved in the innate inflammatory reaction to lipid infiltration by activating the Wnt pathway and promoting lipid uptake, leading to the formation of foam cells [55]. It is possible that the deregulation of LRP5 in TAMs contributes to the intracellular accumulation of fatty acids in lipid droplets observed in the present study.

Finally, the dramatic upregulation of PDK4 probably affect energy metabolism in TAMs such that glucose catabolism is shifted towards glycolysis and lactate production (Warburg effect) [56]. This would render TAMs largely independent from the availability of oxygen, thus endowing the cells with the ability to cope with the hypoxic conditions frequently encountered in the tumor microenvironment.

Our data also show that a large number of target genes that are deregulated by ovarian cancer ascites are repressed by inverse PPAR $\beta / \delta$ agonists, with PT-S264 being able to suppress these genes below the basal level observed in the absence of ascites. Since several of these genes have functions in disease-associated processes as discussed above, inverse PPAR $\beta / \delta$ agonists may represent invaluable experimental tools to interfere with the tumorpromoting effects of the ovarian cancer microenvironment.

\section{Expression of indirect PPAR $\beta / \delta$ target genes in TAMs}

A large group of $\operatorname{PPAR} \beta / \delta$ target genes in macrophages is repressed by $\operatorname{PPAR} \beta / \delta$ agonists independent of direct DNA contacts (see Introduction). These genes are mostly associated with pro-inflammatory functions exerted by macrophages. In TAMs these inverse target genes are also frequently deregulated and refractory to synthetic ligands. However, the underlying mechanisms are complex, as indicated by the extreme variability of expression levels, ligand inducibility and ascites effects observed for different genes as well as individual patients (see Suppl. Figures S3 and S4 for examples). It is likely that the inverse target genes are highly prone to such variations, since they are regulated by multiple signaling pathways that are triggered by numerous cytokines whose concentrations are highly divergent among patients. It is obvious that these variabilities contribute to the observed heterogeneity, in many cases presumably without a significant contribution of PPAR $\beta / \delta$ itself. To understand the mechanistic basis of the altered transcriptome of inverse PPAR $\beta / \delta$ target genes in TAMs it will be necessary to perform in-depth analyses of transcription factor occupancy and epigenetic modifications at individual genes and relate this data to specific pathways and mediators. 


\section{MATERIALS AND METHODS}

\section{Ligands}

L165,041 was purchased from Biozol. ST247 was synthesized as described [20, 57]. The inverse PPAR $\beta / \delta$ agonist PT-S264 is an optimized derivative of ST247 with improved plasma stability (Toth et al., manuscript submitted). Synthetic ligands were used at a concentration of $1 \mu \mathrm{M}$ in all experiments unless indicated otherwise. Cells were treated for $24 \mathrm{~h}$ unless indicated otherwise. PUFAs were obtained from Biomol.

\section{Mice}

Ppard null and wt mice were generated by crossing floxed Ppard mice [58] and Sox2-Cre mice [59] as described [60]. Sox2-Cre mice were obtained from Jackson Laboratory (Bar Harbor, Maine), the floxed Ppard mouse strain was kindly provided by Dr. R. Evans (Salk Institute, La Jolla, CA). For genotyping the following primers were used: Ppard intron 3 (forward: GGC TGG GTC ACA AGA GCT ATT GTC TC), Ppard exon 4 (forward: GGC GTG GGG ATT TGC CTG CTT CA); Ppard intron 4 (reverse: GAG CCG CCT CTC GCC ATC CTT TCA G; fragment sizes: Ppard wt: 360 bp; Ppard floxed: 400 bp; Ppard ko: 240 bp; Cre (forward: CCT GGA AAA TGC TTC TGT CCG; reverse: CAG GGT GTT ATA AGC AAT CCC); fragment size: 390 bp.

\section{Patient samples}

Peripheral blood mononuclear cells (PBMCs) were obtained from healthy adult volunteers. Ascites was collected from untreated high-grade serous ovarian carcinoma patients undergoing surgery at the University Hospital Marburg. Informed consent was obtained from all patients according to the protocols approved by the institutional ethics committee.

\section{Isolation of $\mathrm{CD}^{+} 4^{+}$cells}

Mononuclear cells were isolated from ascites and peripheral blood by Lymphocyte Separation Medium 1077 (PromoCell) density gradient centrifugation and purified by magnetic cell sorting (MACS) using CD14 microbeads (Miltenyi Biotech) or adherence selection on cell culture dishes for $30 \mathrm{~min}$. For ChIP experiments, TAMs were purified by adherence selection. The purity of $\mathrm{CD} 14^{+}$cells was $>90 \%$. Purified TAMs and MDMs were analyzed by FACS, lysed in PeqGold (Peqlab) for RNA preparation or cultured as described below.

\section{Cell culture and cytokine treatment of TAMs and} MDMs

$\mathrm{CD} 14^{+}$monocytes and TAMs were cultured either in RPMI1640 with 10\% fetal bovine serum (FCS; R10 medium), serum-free RPMI1640 (R0 medium) or in serum-free macrophage X-VIVO 10 medium (XV0 medium) (Biozym Scientific). Monocyte-derived macrophages (MDMs) were differentiated from $\mathrm{CD} 14^{+}$ monocytes of healthy volunteers for $5-7 \mathrm{~d}$ at $1 \times 10^{6}$ cells/ $\mathrm{ml}$. HEY ovarian cancer cells (ATCC) were maintained in DMEM plus $10 \%$ FCS.

\section{Lipidomic analysis}

Ascites samples $(1 \mathrm{ml})$ were spiked with 100 $\mu \mathrm{l}$ deuterated internal standard and extracted using solid reverse phase extraction columns (Strata-X 33, Phenomenex). Fatty acids derivatives were eluted into 1.0 $\mathrm{ml}$ of methanol, lyophilized and resuspended in $100 \mathrm{ml}$ of water/acetonitrile/formic acid (70:30:0.02, v/v/v; solvent A) and analyzed by LC-MS/MS on an Agilent 1290 separation system. Samples were separated on a Synergi reverse-phase C18 column $(2.1 \times 250 \mathrm{~mm}$; Phenomenex $)$ using a gradient as follows: flow rate $=0.3 \mu \mathrm{l} / \mathrm{min}, 1 \mathrm{~min}$ (acetonitrile/isopropyl alcohol, 50:50, v/v; solvent B), 3 min (25\% solvent B), 11 min (45\% solvent B), 13 min (60\% solvent B), 18 min ( $75 \%$ solvent B), 18.5 min $(90 \%$ solvent B), 20 min ( $90 \%$ solvent B), $21 \mathrm{~min}$ ( $0 \%$ solvent). The separation system was coupled to an electrospray interface of a QTrap 5500 mass spectrometer (AB Sciex). Compounds were detected in scheduled multiple reaction monitoring mode. For quantification a 12-point calibration curve for each analyte was used. Data analysis was performed using Analyst (v1.6.1) and MultiQuant (v2.1.1) (AB Sciex).

\section{Immunoblotting}

Immunoblots were performed following standard protocols using the following antibodies: $\alpha$-PPAR $\beta / \delta$ (sc-74517; Santa Cruz, Heidelberg, Germany), $\alpha$-PDK4 (ab110336; Abcam, Cambridge, United Kingdom), $\alpha$-LDH (sc-33781; Santa Cruz, Heidelberg, Germany), $\alpha$-rabbit $\operatorname{IgG}$ HRP-linked $\mathrm{AB}$ and $\alpha$-mouse IgG HRP-linked AB (cs7074, cs7076; Cell Signaling, NEB, Frankfurt, Germany). ChemiDoc MP system and Image Lab software version 5 (Bio-Rad, München, Germany) were used for detection and quantification.

\section{Quantification of secreted ANGPTL4 protein}

ANGPTL4 levels in ascites from ovarian cancer patients were determined by ELISA (Aviscera Bioscience, 
Santa Clara, CA), according to the instructions of the manufacturer. The antibody used in this kit recognizes the bioactive C-terminal processing product (cANGPTL4).

\section{Nile Red staining}

Cells were stained for 10 minutes at $37^{\circ} \mathrm{C}$ with 500 nM Nile Red (Biomol, Hamburg, Germany) in PBS and visualized using a Leica DM5000 B microscope. Nuclei were stained using Vecta Shield with DAPI (Biozol, Eching, Germany). For quantification the percentage of Nile Red positive cells was determined by counting 20 faces per donor or patient per treatment.

\section{Luciferase reporter assay}

The PDK4 upstream enhancer region was cloned into pGL3-TATAi [61] via $K p n I$ sites using the following primers:

5'-AAAGGTACCAAATGCTGAGTTTGGGCAAC and 5'-AAAGGTACCAGCCTTGTGAGCAACCAAAG. PPREs were mutated with the following primers 5' -CAGGCTAAGTTGGTGTATGGTCAGTCCCACACC, 5'-GAAGTTTAGTAGGTGTACGGTCACTGCTGCCGA and5'-AGAGCTCACTAGGGGTATGGTCGGGGAGAC $\mathrm{CAAG}$, and their respective reverse complement primers. HEY1 cells were transfected with the indicated reporter vector and $\mathrm{pEF6/V5-His-TOPO/lacZ} \mathrm{(Life} \mathrm{Technologies)}$ as described [18] and incubated overnight in DMEM with $2 \%$ FCS. On the next day, cells were washed with PBS and received either fresh medium with or without $1 \mu \mathrm{M}$ L165,041 or ascites for $24 \mathrm{~h}$. Lysates were prepared and measured according to the manufacturer's instructions (Beetle Juice Big and $\beta$-Gal Juice PLUS Kit for normalization; pjk $\mathrm{GmbH}$ ) with an Orion L luminometer (Berthold).

\section{RT-qPCR and RNA-Seq}

cDNA isolation and qPCR analyses were performed as described [20]. L27 was used for normalization. Primer sequences are listed in Suppl. Table S1. RNA-Seq was carried out as described elsewhere [28]. Sequencing data were deposited at EBI ArrayExpress (accession number TAM data: E-MTAB-3167; MDM data: E-MTAB-3114 and E-MTAB-3398). Data were quantile normalized using all RNA-Seq datasets. Gene model data were retrieved from Ensembl revision 74.

\section{Bioinformatic analysis of RNA-Seq data}

We sequenced 10 TAMs samples from 10 patients directly after harvesting ("in vivo"), one additional TAM sample was used for ligand response experiments in autologous ascites ("in vitro"; L165,041, ST247 and DMSO). In addition to previously described MDM ligand response experiments from two donors [28] in R10 and X0 medium (L165,041, ST247, PT-S264, DMSO), we performed three additional sets from three donors in R10 (L165,041, PT-S264 and DMSO control). ST247 was used at a concentrations of $300 \mathrm{nM}$, all others at $1 \mu \mathrm{M}$.

Genes were considered for differential expression analyses only if they had an FPKM of at least 0.3 and a minimum of 50 tags in at least one sample. LogFC values for ligand experiments were calculated pairwise for individual donors. For ligand regulation in MDMs (Figure 2B) a $\log \mathrm{FC}$ of at least 0.7 in 4 out of 5 replicates was required. Figure $2 \mathrm{C}$ shows median pairwise $\log \mathrm{FC}$ data. Regulated target genes in MDMs $(n=195$; Figures $2 \mathrm{E}$ and $3 \mathrm{~A}$ ) were defined as genes showing regulation in at least one of the following comparisons: agonist vs DMSO control (up regulated), inverse agonist vs DMSO control (down regulated) or agonist $v s$ inverse agonist (up regulated). Figure $3 \mathrm{~A}$ shows median FPKM values of 10 TAM samples and 5 MDM DMSO control samples. In Figure 3B and 3C, "up in TAM in vivo" is a subset of the canonical target genes that showed a 2-fold (1 logFC unit) difference between TAMs and MDMs. Table S5 was filtered based on t-tests between 10 TAM in vitro samples and 5 MDM DMSO samples (FDR/Benjamini-Hochberg $\leq 0.05$ ). The set "up in TAM in vitro" is similarly defined as canonical target genes that (i) were upregulated $(0.7$ $\operatorname{logFC}$ ) in TAM/DMSO compared to the two previously reported MDM/DMSO samples, and (ii) showed an at least 0.5 units higher FPKM value in the TAM sample compared to both MDM samples. Agonist refractory genes (Figure 3C) are agonist inducible genes in MDMs that showed no such regulation (same $\operatorname{logFC}$ threshold) or less than $50 \%$ induction (fold change) by L165,041 in TAMs relative to MDMs.

\section{ChIP-PCR and ChIP-Seq}

ChIP was performed and evaluated as described using the following antibodies: IgG pool, I5006 (Sigma Aldrich); $\alpha$-PPAR $\beta / \delta$, sc-7197; $\alpha$-RXR, sc-774 (Santa Cruz, Heidelberg, Germany). ChIP-Seq, mapping of ChIPSeq reads and peak calling were carried out as described [28].

\section{Bioinformatic analysis of ChIP-Seq data}

ChIP-Seq peaks were filtered for at least 30 deduplicated tags and a fold change (FC) over IgG of $\geq 2$ (normalized total read counts). Regions were considered bound by $\mathrm{PPAR} \beta / \delta$ in TAMs if they enrichment sites were observed in at least two out of three TAM samples sequenced. PPAR $\beta / \delta$ binding in MDMs has been described elsewhere [28]. For Figure 2E, PPAR $\beta / \delta$-occupied genes 
were identified as genes with a transcription start site close to, or within $50 \mathrm{~kb}$ of, an enrichment site. All genomic sequence and gene annotation data was retrieved from Ensembl revision 74 .

\section{Functional annotations and pathway analyses}

Functional annotations and pathway analyses were performed using the Ingenuity Pathway Analysis (IPA) application and knowledge database (Qiagen Redwood City, CA, USA). Results were sorted according to p-value of overlap (minimum 0.001) and activation Z-scores ( $\leq$ 2.0 or $\geq+2.0$ ) Sequencing data were deposited at EBI ArrayExpress (accession number E-MTAB-3166).

\section{Statistical analysis of experimental data}

Data are presented as the average of replicates $(n=$ 3 unless indicated otherwise) with error bars indicating standard deviations and horizontal lines in dot plots representing averages. Comparative data were statistically analyzed by Student's $t$-test (two-sided, equal variance) and results expressed as follows: ns, not significant ( $p \geq$ $0.05) ; * p<0.05, * * p<0.01$ or $* * * p<0.001$.

\section{Survival-associated gene expression analysis}

Associations between gene expression and relapsefree survival of ovarian cancer patients were analyzed using the web based tool "KM Plotter" (http://kmplot.com/ analysis/index.php? $p=$ service \&cancer $=$ ovar) [62] with the following settings: 'auto select best cutoff', stage: $2+3+4$, histology: serous, dataset: TCGA; other settings: default). Logrank Mantel-Cox test (p-values), logrank Hazard Ratio (HR) and median survival times were calculated using the GraphPad Prism software.

\section{ACKNOWLEDGMENTS}

We are grateful to Dr. Robert Geffers (HelmholtzZentrum für Infektionsforschung, Braunschweig, Germany) for valuable discussions on ChIP-seq library synthesis and to Margitta Alt, Traute Plaum and Achim Allmeroth for expert technical assistance.

\section{GRANT SUPPORT}

This research was supported by research grants from the Deutsche Forschungsgemeinschaft to RM (MU601/13), the Wilhelm-Sander-Stiftung to SMB, SR and UW, the Stiftung P.E. Kempkes and the Universitätsklinikum Giessen-Marburg (UKGM Forschungsförderung) to TA, SR and UW.

\section{CONFLICTS OF INTEREST}

All authors have nothing to disclose.

\section{Abbreviations}

AA, arachidonic acid; ALA; $\alpha$-linolenic acid; ANGPTL4: angiopoietin-like 4; ChIP, chromatin immune precipitation; BMDM: marrow-derived macrophage; ChIP-Seq, ChIP sequencing; D10, DMEM with 10\% FCS; DHA, docosahexaenoic acid; EPA, eicosapentaenoic acid; FCS, fetal calf serum; 15-HETE, 15-hydroxyeicosatetraenoic acid; IPA: Ingenuity Pathway Analysis; 6-kPGF ${ }_{1 \alpha}$ : 6-keto-prostglandin $\mathrm{F}_{1 \alpha}$; LA: linoleic acid; MDM, monocyte-derived macrophage; NFкB: nuclear factor $\kappa \mathrm{B}$; PDK4, pyruvate dehydrogenase 4; PPAR, peroxisome proliferator-activated receptor; $\operatorname{PPAR} \beta / \delta$, proliferator-activated receptor $\beta / \delta$; PPRE, PPAR response element; PUFA, polyunsaturated fatty acid; RNA-Seq, RNA sequencing; RT-qPCR, reverse transcriptase quantitative $\mathrm{PCR}$; $\mathrm{RXR}$, retinoid $\mathrm{X}$ receptor; TAM: tumor-associated macrophage; XV0: X-VIVO 10 medium without serum.

\section{REFERENCES}

1. Condeelis J and Pollard JW. Macrophages: obligate partners for tumor cell migration, invasion, and metastasis. Cell. 2006; 124:263-266.

2. Hagemann T, Biswas SK, Lawrence T, Sica A and Lewis CE. Regulation of macrophage function in tumors: the multifaceted role of NF-kappaB. Blood. 2009; 113:31393146.

3. Pollard JW. Tumour-educated macrophages promote tumour progression and metastasis. Nat Rev Cancer. 2004; 4:71-78.

4. Sica A and Mantovani A. Macrophage plasticity and polarization: in vivo veritas. J Clin Invest. 2012; 122:787795.

5. Gabrilovich DI, Ostrand-Rosenberg S and Bronte V. Coordinated regulation of myeloid cells by tumours. Nat Rev Immunol. 2012; 12:253-268.

6. Xue J, Schmidt SV, Sander J, Draffehn A, Krebs W, Quester I, De Nardo D, Gohel TD, Emde M, Schmidleithner L, Ganesan H, Nino-Castro A, Mallmann MR, Labzin L, Theis H, Kraut M, et al. Transcriptome-based network analysis reveals a spectrum model of human macrophage activation. Immunity. 2014; 40:274-288.

7. Qian BZ and Pollard JW. Macrophage diversity enhances tumor progression and metastasis. Cell. 2010; 141:39-51.

8. Reinartz S, Schumann T, Finkernagel F, Wortmann A, Jansen JM, Meissner W, Krause M, Schworer AM, Wagner U, Muller-Brusselbach S and Muller R. Mixed-polarization phenotype of ascites-associated macrophages in human 
ovarian carcinoma: Correlation of CD163 expression, cytokine levels and early relapse. Int J Cancer. 2014; 134:32-42.

9. Kostadinova R, Wahli W and Michalik L. PPARs in diseases: control mechanisms of inflammation. Curr Med Chem. 2005; 12:2995-3009.

10. Wahli W and Michalik L. PPARs at the crossroads of lipid signaling and inflammation. Trends Endocrinol Metab. 2012; 23:351-363.

11. Peters JM, Lee SS, Li W, Ward JM, Gavrilova O, Everett C, Reitman ML, Hudson LD and Gonzalez FJ. Growth, adipose, brain, and skin alterations resulting from targeted disruption of the mouse peroxisome proliferator-activated receptor beta(delta). Mol Cell Biol. 2000; 20:5119-5128.

12. Chong HC, Tan MJ, Philippe V, Tan SH, Tan CK, Ku CW, Goh YY, Wahli W, Michalik L and Tan NS. Regulation of epithelial-mesenchymal IL-1 signaling by PPARbeta/delta is essential for skin homeostasis and wound healing. J Cell Biol. 2009; 184:817-831.

13. Kang K, Reilly SM, Karabacak V, Gangl MR, Fitzgerald $\mathrm{K}$, Hatano B and Lee CH. Adipocyte-derived Th2 cytokines and myeloid PPARdelta regulate macrophage polarization and insulin sensitivity. Cell Metab. 2008; 7:485-495.

14. Odegaard JI, Ricardo-Gonzalez RR, Red Eagle A, Vats D, Morel CR, Goforth MH, Subramanian V, Mukundan L, Ferrante AW and Chawla A. Alternative M2 activation of Kupffer cells by PPARdelta ameliorates obesity-induced insulin resistance. Cell Metab. 2008; 7:496-507.

15. Peters JM, Shah YM and Gonzalez FJ. The role of peroxisome proliferator-activated receptors in carcinogenesis and chemoprevention. Nat Rev Cancer. 2012; 12:181-195.

16. Xu HE, Lambert MH, Montana VG, Parks DJ, Blanchard SG, Brown PJ, Sternbach DD, Lehmann JM, Wisely GB, Willson TM, Kliewer SA and Milburn MV. Molecular recognition of fatty acids by peroxisome proliferatoractivated receptors. Mol Cell. 1999; 3:397-403.

17. Lim H, Gupta RA, Ma WG, Paria BC, Moller DE, Morrow JD, DuBois RN, Trzaskos JM and Dey SK. Cyclo-oxygenase-2-derived prostacyclin mediates embryo implantation in the mouse via PPARdelta. Genes Dev. 1999; 13:1561-1574.

18. Naruhn S, Meissner W, Adhikary $T$, Kaddatz $\mathrm{K}$, Klein T, Watzer B, Müller-Brüsselbach S and Müller R. 15-hydroxyeicosatetraenoic acid is a preferential peroxisome proliferator-activated receptor $\beta / \delta$ agonist. Mol Pharmacol. 2010; 77:171-184.

19. Adhikary T, Kaddatz K, Finkernagel F, Schönbauer A, Meissner W, Scharfe M, Jarek M, Blöcker H, MüllerBrüsselbach S and Müller R. Genomewide analyses define different modes of transcriptional regulation by peroxisome proliferator-activated receptor-beta/delta (PPARbeta/delta). PLoS One. 2011; 6:e16344.

20. Naruhn S, Toth PM, Adhikary T, Kaddatz K, Pape V, Dörr
S, Klebe G, Müller-Brüsselbach S, Diederich WE and Müller R. High-affinity peroxisome proliferator-activated receptor beta/delta-specific ligands with pure antagonistic or inverse agonistic properties. Mol Pharmacol. 2011; 80:828838 .

21. Adhikary T, Brandt DT, Kaddatz K, Stockert J, Naruhn S, Meissner W, Finkernagel F, Obert J, Lieber S, Scharfe M, Jarek M, Toth PM, Scheer F, Diederich WE, Reinartz S, Grosse R, et al. Inverse PPARbeta/delta agonists suppress oncogenic signaling to the ANGPTL4 gene and inhibit cancer cell invasion. Oncogene. 2013; 32:5241-5252.

22. Oishi Y, Manabe I, Tobe K, Ohsugi M, Kubota T, Fujiu K, Maemura K, Kubota N, Kadowaki T and Nagai R. SUMOylation of Kruppel-like transcription factor 5 acts as a molecular switch in transcriptional programs of lipid metabolism involving PPAR-delta. Nat Med. 2008; 14:656666.

23. Lee CH, Chawla A, Urbiztondo N, Liao D, Boisvert WA, Evans RM and Curtiss LK. Transcriptional repression of atherogenic inflammation: modulation by PPARdelta. Science. 2003; 302:453-457.

24. Planavila A, Rodriguez-Calvo R, Jove M, Michalik L, Wahli W, Laguna JC and Vazquez-Carrera M. Peroxisome proliferator-activated receptor beta/delta activation inhibits hypertrophy in neonatal rat cardiomyocytes. Cardiovasc Res. 2005; 65:832-841.

25. Westergaard M, Henningsen J, Johansen C, Rasmussen S, Svendsen ML, Jensen UB, Schroder HD, Staels B, Iversen L, Bolund L, Kragballe K and Kristiansen K. Expression and localization of peroxisome proliferator-activated receptors and nuclear factor kappaB in normal and lesional psoriatic skin. J Invest Dermatol. 2003; 121:1104-1117.

26. Ding G, Cheng L, Qin Q, Frontin S and Yang Q. PPARdelta modulates lipopolysaccharide-induced TNFalpha inflammation signaling in cultured cardiomyocytes. J Mol Cell Cardiol. 2006; 40:821-828.

27. Stockert J, Wolf A, Kaddatz K, Schnitzer E, Finkernagel F, Meissner W, Müller-Brüsselbach S, Kracht M and Müller R. Regulation of TAK1/TAB1-Mediated IL-1beta Signaling by Cytoplasmic PPARbeta/delta. PLoS One. 2013; 8:e63011.

28. Adhikary T, Wortmann A, Schumann T, Finkernagel F, Lieber S, Roth K, Toth PM, Diederich WE, Nist A, Stiewe T, Kleinesudeik L, Reinartz S, Müller-Brüsselbach S and Müller R. The transcriptional PPAR $\beta / \delta$ network in human macrophages defines a unique agonist-induced activation state. Nucl Acids Res. 2015:in press.

29. Yamashiro S, Takeya M, Nishi T, Kuratsu J, Yoshimura T, Ushio Y and Takahashi K. Tumor-derived monocyte chemoattractant protein-1 induces intratumoral infiltration of monocyte-derived macrophage subpopulation in transplanted rat tumors. Am J Pathol. 1994; 145:856-867.

30. Silzle T, Kreutz M, Dobler MA, Brockhoff G, Knuechel $\mathrm{R}$ and Kunz-Schughart LA. Tumor-associated fibroblasts recruit blood monocytes into tumor tissue. Eur J Immunol. 
2003; 33:1311-1320.

31. Murdoch C, Giannoudis A and Lewis CE. Mechanisms regulating the recruitment of macrophages into hypoxic areas of tumors and other ischemic tissues. Blood. 2004; 104:2224-2234

32. Ahmed N and Stenvers KL. Getting to Know Ovarian Cancer Ascites: Opportunities for Targeted Therapy-Based Translational Research. Front Oncol. 2013; 3:256.

33. Degenhardt T, Saramaki A, Malinen M, Rieck M, Vaisanen S, Huotari A, Herzig KH, Müller R and Carlberg C. Three Members of the Human Pyruvate Dehydrogenase Kinase Gene Family Are Direct Targets of the Peroxisome Proliferator-activated Receptor $\beta / \delta$. J Mol Biol. 2007.

34. Network TCGAR. Integrated genomic analyses of ovarian carcinoma. Nature. 2011; 474:609-615.

35. Padua D, Zhang XH, Wang Q, Nadal C, Gerald WL, Gomis RR and Massague J. TGFbeta primes breast tumors for lung metastasis seeding through angiopoietin-like 4. Cell. 2008; 133:66-77.

36. Gupta RA, Tan J, Krause WF, Geraci MW, Willson TM, Dey SK and DuBois RN. Prostacyclin-mediated activation of peroxisome proliferator-activated receptor delta in colorectal cancer. Proc Natl Acad Sci U S A. 2000; 97:13275-13280.

37. Vosper H, Patel L, Graham TL, Khoudoli GA, Hill A, Macphee CH, Pinto I, Smith SA, Suckling KE, Wolf CR and Palmer $\mathrm{CN}$. The peroxisome proliferator-activated receptor delta promotes lipid accumulation in human macrophages. J Biol Chem. 2001; 276:44258-44265.

38. Caselmann WH and Jungst D. Isolation and characterization of a cellular protein-lipid complex from ascites fluid caused by various neoplasms. Cancer Res. 1986; 46:1547-1552.

39. Yam D, Ben-Hur H, Dgani R, Fink A, Shani A and Berry EM. Subcutaneous, omentum and tumor fatty acid composition, and serum insulin status in patients with benign or cancerous ovarian or endometrial tumors. Do tumors preferentially utilize polyunsaturated fatty acids? Cancer Lett. 1997; 111:179-185.

40. Gansler TS, Hardman W, 3rd, Hunt DA, Schaffel S and Hennigar RA. Increased expression of fatty acid synthase (OA-519) in ovarian neoplasms predicts shorter survival. Hum Pathol. 1997; 28:686-692.

41. Tania M, Khan MA and Song Y. Association of lipid metabolism with ovarian cancer. Curr Oncol. 2010; 17:611.

42. Nieman KM, Kenny HA, Penicka CV, Ladanyi A, BuellGutbrod R, Zillhardt MR, Romero IL, Carey MS, Mills GB, Hotamisligil GS, Yamada SD, Peter ME, Gwin K and Lengyel E. Adipocytes promote ovarian cancer metastasis and provide energy for rapid tumor growth. Nat Med. 2011; 17:1498-1503.

43. Fraser DA, Thoen J, Rustan AC, Forre O and KjeldsenKragh J. Changes in plasma free fatty acid concentrations in rheumatoid arthritis patients during fasting and their effects upon T-lymphocyte proliferation. Rheumatology (Oxford). 1999; 38:948-952.

44. Mandard S, Zandbergen F, van Straten E, Wahli W, Kuipers F, Muller M and Kersten S. The fasting-induced adipose factor/angiopoietin-like protein 4 is physically associated with lipoproteins and governs plasma lipid levels and adiposity. J Biol Chem. 2006; 281:934-944.

45. Kaddatz K, Adhikary T, Finkernagel F, Meissner W, Müller-Brüsselbach $\mathrm{S}$ and Müller R. Transcriptional profiling identifies functional interactions of TGF $\beta$ and PPAR $\beta / \delta$ signaling: synergistic induction of ANGPTL4 transcription. J Biol Chem. 2010; 285:29469-29479.

46. Zhu P, Goh YY, Chin HF, Kersten $\mathrm{S}$ and Tan NS. Angiopoietin-like 4: a decade of research. Biosci Rep. 2012; 32:211-219.

47. Hu Z, Fan C, Livasy C, He X, Oh DS, Ewend MG, Carey LA, Subramanian S, West R, Ikpatt F, Olopade OI, van de Rijn $M$ and Perou CM. A compact VEGF signature associated with distant metastases and poor outcomes. BMC Med. 2009; 7:9.

48. Zhu P, Tan MJ, Huang RL, Tan CK, Chong HC, Pal M, Lam CR, Boukamp P, Pan JY, Tan SH, Kersten S, Li HY, Ding JL and Tan NS. Angiopoietin-like 4 Protein Elevates the Prosurvival Intracellular $\mathrm{O}(2)(-): \mathrm{H}(2) \mathrm{O}(2)$ Ratio and Confers Anoikis Resistance to Tumors. Cancer Cell. 2011; 19:401-415.

49. Tanaka T, Tahara-Hanaoka S, Nabekura T, Ikeda K, Jiang S, Tsutsumi S, Inagaki T, Magoori K, Higurashi T, Takahashi H, Tachibana K, Tsurutani Y, Raza S, Anai M, Minami T, Wada Y, et al. PPARbeta/delta activation of CD300a controls intestinal immunity. Sci Rep. 2014; $4: 5412$.

50. Higuchi Y, Setoguchi M, Yoshida S, Akizuki S and Yamamoto S. Enhancement of c-fos expression is associated with activated macrophages. Oncogene. 1988; 2:515-521.

51. Wiezlak M, Diring J, Abella J, Mouilleron S, Way M, McDonald NQ and Treisman R. G-actin regulates the shuttling and PP1 binding of the RPEL protein Phactr1 to control actomyosin assembly. J Cell Sci. 2012; 125:58605872 .

52. Zhang Y, Wang Z, Chen M, Peng L, Wang X, Ma Q, Ma F and Jiang B. MicroRNA-143 targets MACC1 to inhibit cell invasion and migration in colorectal cancer. Mol Cancer. 2012; 11:23.

53. Lee D, Lee HS, Yang SJ, Jeong H, Kim DY, Lee SD, Oh JW, Park D and Kim MG. PRSS14/Epithin is induced in macrophages by the IFN-gamma/JAK/STAT pathway and mediates transendothelial migration. Biochem Biophys Res Commun. 2011; 405:644-650.

54. Tamai K, Semenov M, Kato Y, Spokony R, Liu C, Katsuyama Y, Hess F, Saint-Jeannet JP and He X. LDLreceptor-related proteins in Wnt signal transduction. Nature. 2000; 407:530-535. 
55. Borrell-Pages M, Romero JC, Juan-Babot $\mathrm{O}$ and Badimon L. Wnt pathway activation, cell migration, and lipid uptake is regulated by low-density lipoprotein receptor-related protein 5 in human macrophages. Eur Heart J. 2011; 32:2841-2850.

56. Grassian AR, Metallo CM, Coloff JL, Stephanopoulos G and Brugge JS. Erk regulation of pyruvate dehydrogenase flux through PDK4 modulates cell proliferation. Genes Dev. 2011; 25:1716-1733.

57. Toth PM, Naruhn S, Pape VF, Dörr SM, Klebe G, Müller R and Diederich WE. Development of Improved PPARbeta/ delta Inhibitors. ChemMedChem. 2012; 7:159-170.

58. Barak Y, Liao D, He W, Ong ES, Nelson MC, Olefsky JM, Boland R and Evans RM. Effects of peroxisome proliferator-activated receptor delta on placentation, adiposity, and colorectal cancer. Proc Natl Acad Sci U S A. 2002; 99:303-308.

59. Hayashi S, Lewis P, Pevny L and McMahon AP. Efficient gene modulation in mouse epiblast using a Sox2Cre transgenic mouse strain. Mech Dev. 2002; 119 Suppl 1:S97-S101.

60. Scholtysek C, Katzenbeisser J, Fu H, Uderhardt S, Ipseiz N, Stoll C, Zaiss MM, Stock M, Donhauser L, Bohm C, Kleyer A, Hess A, Engelke K, David JP, Djouad F, Tuckermann JP, et al. PPARbeta/delta governs Wnt signaling and bone turnover. Nat Med. 2013:19.

61. Jérôme V and Müller R. Tissue-specific, cell cycleregulated chimeric transcription factors for the targeting of gene expression to tumor cells. Hum Gene Ther. 1998; 9:2653-2659.

62. Gyorffy B, Lanczky A and Szallasi Z. Implementing an online tool for genome-wide validation of survivalassociated biomarkers in ovarian-cancer using microarray data from 1287 patients. Endocr Relat Cancer. 2012; 19:197-208. 